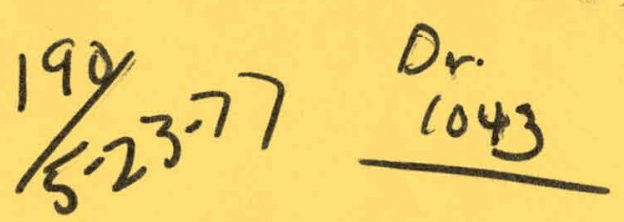

\title{
DEALS: A DEMOUNTABLE EXTERNALLY ANCHORED LOW STRESS SUPERCONDUCTING MAGNET SYSTEM FOR FUSION REACTORS
}

James Powell, David Hsieh, and John Lehner

January 1977

\section{DEPARTMENT OF APPLIED SCIENCE}

BROOKHAVEN NATIONAL LABORATORY ASSOCIATED UNIVERSITIES, INC. 


\section{DISCLAIMER}

This report was prepared as an account of work sponsored by an agency of the United States Government. Neither the United States Government nor any agency Thereof, nor any of their employees, makes any warranty, express or implied, or assumes any legal liability or responsibility for the accuracy, completeness, or usefulness of any information, apparatus, product, or process disclosed, or represents that its use would not infringe privately owned rights. Reference herein to any specific commercial product, process, or service by trade name, trademark, manufacturer, or otherwise does not necessarily constitute or imply its endorsement, recommendation, or favoring by the United States Government or any agency thereof. The views and opinions of authors expressed herein do not necessarily state or reflect those of the United States Government or any agency thereof. 


\section{DISCLAIMER}

Portions of this document may be illegible in electronic image products. Images are produced from the best available original document. 
BNL 50616

(Controlled Thermonuclear Processes and Plasma Physics - TID-4500)

\section{DEALS: A DEMOUNTABLE EXTERNALLY ANCHORED LOW STRESS SUPERCONDUCTING MAGNET SYSTEM FOR FUSION REACTORS}

James Powell, David Hsieh, and John Lehner

January 1977

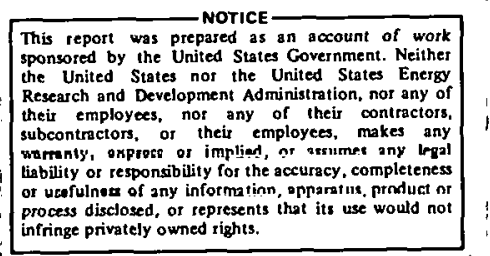

DEPARTMENT OF APPLIED SCIENCE

BROOKHAVEN NATIONAL LABORATORY

ASSOCIATED UNIVERSITIES, INC.

UNDER CONTRACT PNO. [Y.76-C.02.0016 WITH THE

UNITED STATES ENERGY RESEARCH AND DEVELOPMENT ADMINISTRATION 
NOT I C E

This report was prepared as an account of work sponsored by the United States Government. Neither the United States nor the United States Energy Research and Development Adminintration, nor any of their employees, nor any of their contractors, subcontractors, or their employees, makes any warranty, express or implied, or assumes any legal liability or responsibility for the accuracy, completeness or usefulness of any information, apparatus, product or process disclosed, or represents that its use would not infringe privately owned rights.

Frinted in the United Statcs of America

Available from

National Technical Information Service

U.S. Department of Commerce

5285 Port Royal Road

Springfield, VA 22161

Price: Printed Copy $\$ 5.00$; Microfiche $\$ 3.00$

March 1977

350 copies 
3. DEALS COIL DESIGN FOR UWMAK-II SIZE REACTOR

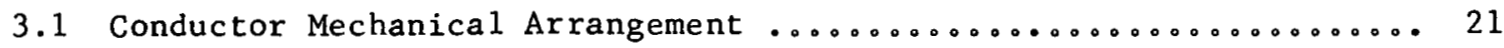

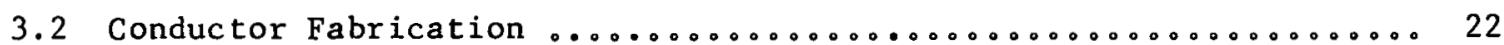

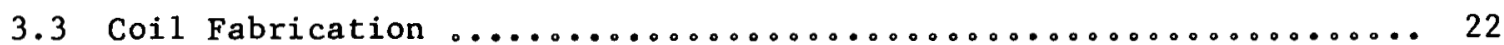

3.4 Coil Segment Joining and Disjoining Operations ............. 23

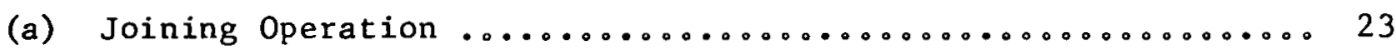

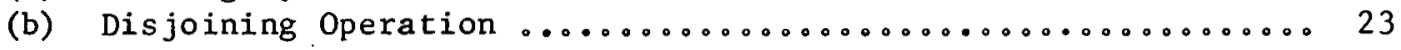

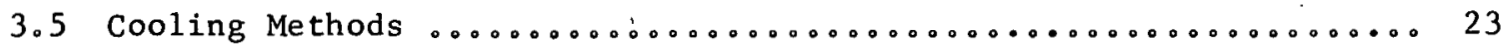



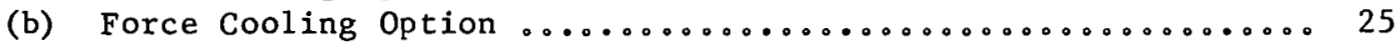

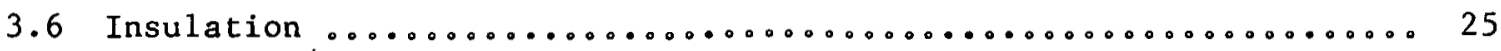

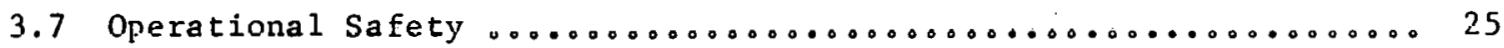

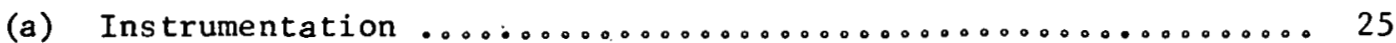

(b) Thermal Equalization Capacity ........................ 26

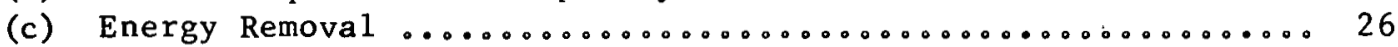

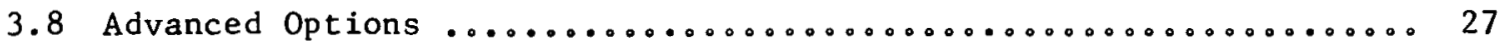

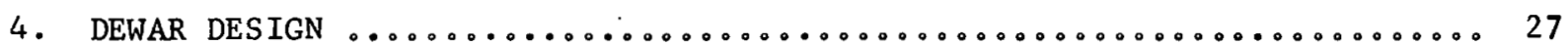

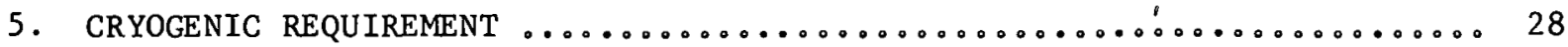




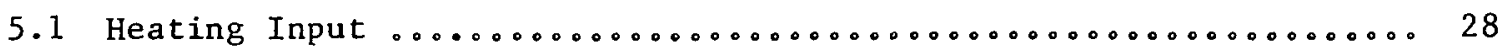

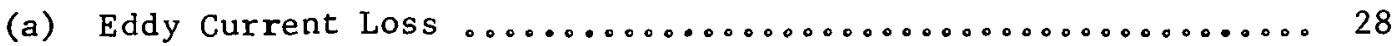

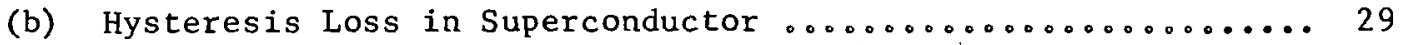

(c) Losses From Conductor Joints ..................... 30

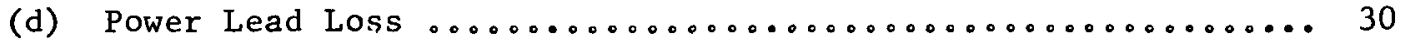

(e) Losses From Instrumentation Penetration .............. 31

(f) Coil Case Support Loss ........................... 31

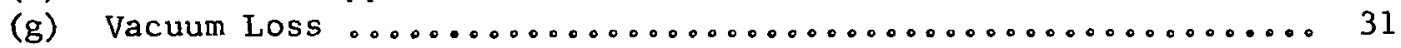

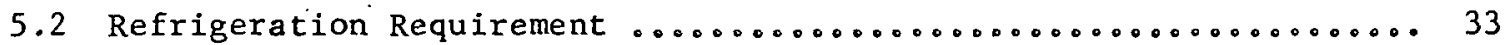

6. DEALS STRUCTURAL ANALYSIS FOR UWMAK-II SIZE REACTOR $\ldots \ldots \ldots \ldots \ldots \ldots \ldots$

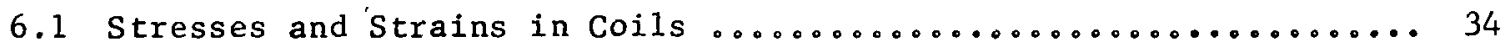

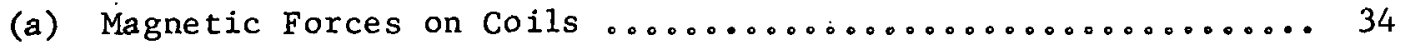

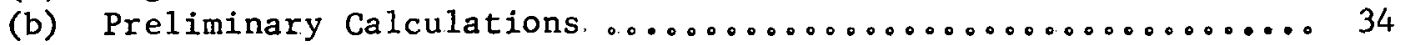

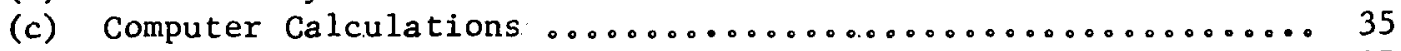

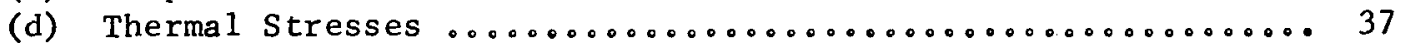

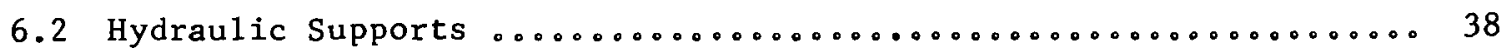

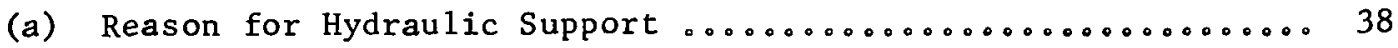

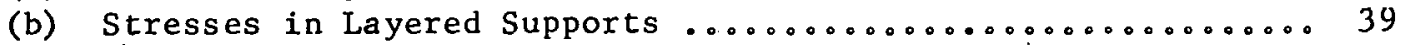

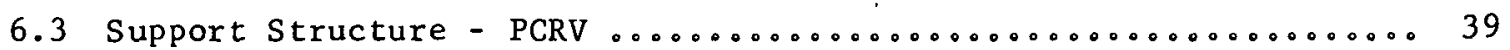

6.4 Central Column Design $\ldots \ldots \ldots \ldots \ldots \ldots \ldots \ldots \ldots \ldots \ldots \ldots \ldots \ldots \ldots \ldots \ldots \ldots$

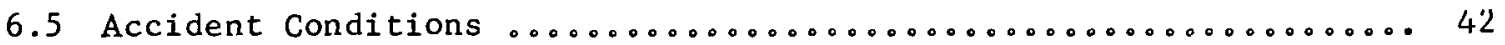

6.6 Assembly and Disassembly Procedures .................... 42

(a) Number of Joints and Ease of Removal $\ldots \ldots \ldots \ldots \ldots \ldots \ldots \ldots \ldots 42$

(b) Other Support and Disassembly Procedures ............... 43

(c) Central Column and Inner Leg Removal Schemes ............ 43

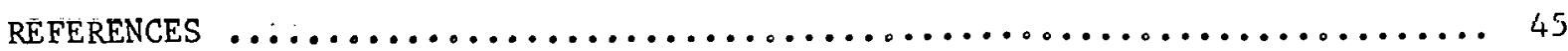

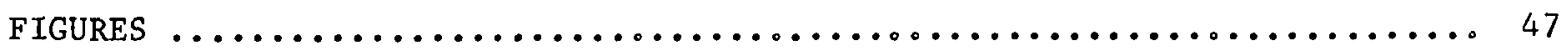




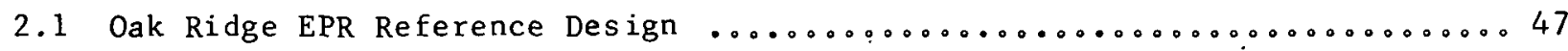

2.2 Plant Availability as a Function of TF Coil Failure Probability .......48

2.3 Schematic of Arrangement of DEALS Coils with PCRV Reinforcement .......48

2.4 Removal Procedure for Failed Section of DEALS TF Coil .............49

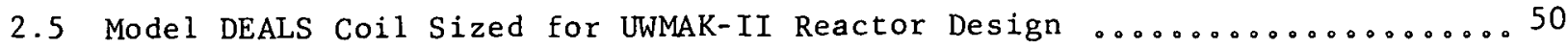

2.6 Comparative Outlines of D-Shape and DEALS TF Coils for UWMAK-II

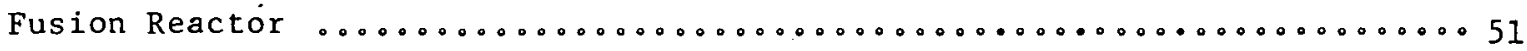

2.7 Non-Planar Arrangement of TF Coils to Maximize Radial and End Access ....52

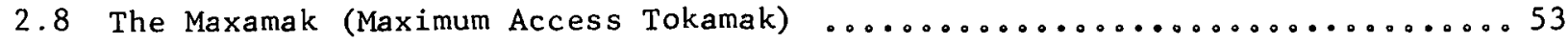

2.9 The Multimak (Multiple Plasma Chamber Tokamak) $\ldots \ldots \ldots \ldots \ldots \ldots \ldots \ldots$

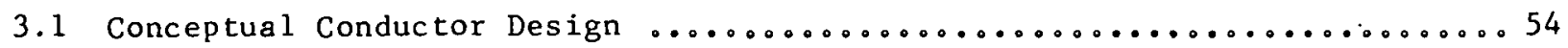

3.2 Schematic Diagram of Conductor Fabrication Process (1) ............ 55

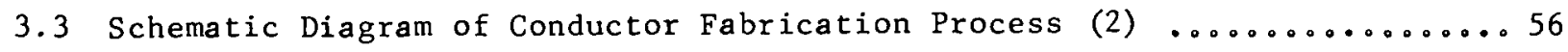

3.4 Schematic Diagram of Conductor Fabrication Process (3) $\ldots \ldots \ldots \ldots \ldots \ldots$

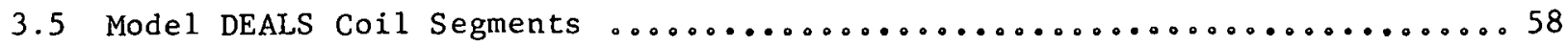

3.6 Schematic Diagram of Coil Segments Joining Process (1) $\ldots \ldots \ldots \ldots \ldots$

3.7 Schematic Diagram of Coil Segments Joining Process (2) ............. 59

3.8 Schematic Diagram of Coil Segments Joining Process (3) ............60

3.9 Conceptual Pool Cooling Channel Design ....................61

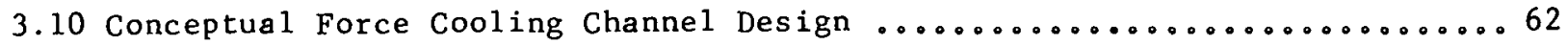

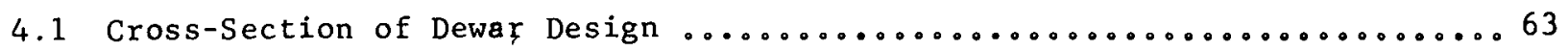

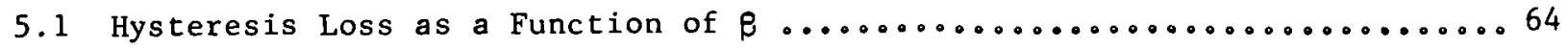

6.1 Finite Element Grid for Whole Coil Stress Analysis ...............65

6.2 Finite Element Grid for Individual loil Leg stress Analysis .........6 65 


\section{LIST OF TABLES}

page

Table 1.1 Benefits and Penalties of Deals Magnet System ............ 2

Table 2.1 Deals Magnet Parameters [UWMAK-II Size] ............. 10

Table 2.2 Deals Structural Parameters [UWMAK-II Size] .......... 11

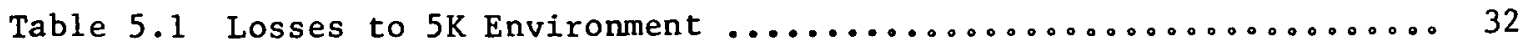




\section{SUMMARY AND CONCLUSIONS}

A new type of superconducting magnet system for large fusion reactors is described in this report. Instead of winding large planar or multi-axis coils, as has been proposed in previous fusion reactor designs, the superconducting coils are made by joining together several pre-fabricated conductor sections. The joints can be unmade and sections removed if they fail. Conductor sections can be made at a factory and shipped to the reactor site for assembly. The conductor stress level in the assembled coil can be kept small by external support of the coil at a number of points along its perimeter, so that the magnetic forces are transmitted to an external warm reinforcement structure. This warm reinforcement structure can also be the primary containment for the fusion reactor, constructed similar to a PCRV (Prestressed Concrete Reactor Vessel) used in fission reactors. Low thermal conductivity, high strength supports are used to transfer the magnetic forces to the external reinforcement through a hydraulic system. The hydraulic supports are movable and can be programmed to accommodate thermal contraction and to minimize stress in the superconducting coil.

The potential benefits and penalties associated with this concept, which is called the DEALS (Demountable Externally Anchored Low Stress) Magnet System, are summarized in Table 1.1. The potential penalties are small, involving a somewhat greater refrigeration load and the necessity of using actively controlled movable supports. The potential benefits are large, and include: the capability of readily removing failed magnets, cheaper magnet construction, much less field fabrications, lower conductor stress, improved access for faster blanket replacement, etc. The DEALS . concept appears very attractive and should be investigated in more detall for a variety of reactor configurations. 


\section{$\underline{\text { Benefits }}$}

- Failed magnet segments can be readily replaced.

- Reliability requirements on superconducting magnets do not have to be as stringent.

- Most of the magnet can be fabricated and tested at a central factory and shipped to reactor sites. Fleld assembly work is much less than for conventional design superconducting magnets.

. Stress in the conductor is significantly less than for conventional design superconducting 'magnets.

- Reinforcement can be a PCRV or other warm structure, Instead of more expensive cold reinforcement.

- Coils can be non-planar and arranged to maximize radial and end access.

- Tokamak reactor can be split at midplane for maximum access when replacing blankets.

- Multiple plasma chambers can be used in one Tokamak TF coil to reduce cost and share rnmmon subsystems (OH power supply, neutral beams, etc.) .

- Thick ceramic insulators can be used in the superconducting coil.

- Brittle high field superconductors can be used at low strain levels. Advanced conductors prepared by non-conventional methods (sputtering etc.) can be used.

- Conductors can be shaped and placed to mfnimize pulsed field losses.

- High conductor current minimizes energy extraction time in quench or accident situation.

\section{Penalties}

- Greater refrigeration renuirements (higher heat leak in leads and supports).

- Movable supports renuired on perimeter of coils. 


\section{INTRODUCTION: APPLICATIONS AND ADVANTAGES OF DEALS}

The toroidal field coils in a Tokamak fusion reactor are interlaced with the blanket, $\mathrm{OH}$ and poloidal field coils, and the neutral beam, coolant and vacuum lines, in a very complex arrangement. Not only does this make construction of the reactor cumbersome, but replacement of a falled TF coil after construction would be extremely difficult, if not impossible. One illustration of this complexity of construction is shown by the ORNL EPR design (1) (Figure 2.1). Replacing a failed TF coil in this reactor would involve removing and replacing a large number of radioactive massive components, with many cuts and seals to be made.

If a TF coil were constructed of several segments which could be readily joined and disjoined, then a failed segment could be replaced relatively rapidly without operations involving other parts of the reactor. The ability to rapidly replace failed segments would permit fusion reactors to operate with considerably less demanding relfability levels for TF coils. Figure 2.2 shows reactor plant availability as a function of failure rate in the TF coils. Three failure scenarios are compared: in the first, failure of a TF coil results in a non-operable reactor because it is impossible to replace the coil. In the second, the TF coil can be replaced, but the reactor is down for a long interval, e.g., 3 years, while massive replacement operations, involving movement of a large portion of the blanket and shield structure, vertical field coils, etc., are carried out. In the third scenario, the TF coil is segmented so that a failed segment can be rcplaced in a month without requiring operations on the rest of the reactor structure. 
For this analysis, each TF coil is assumed to have an independent probability, $P_{1}$, of having a non-repairable failure per year of operation. For example, a non-repairable failure could result from arcing, breakage, etc., inside the superconducting winding. A vacuum leak in the TF coll dewar might or might not be repairable, depending on the nature of the leak and the TF coil design. For an operating reactor the number of failures of the TF coil system, per operating year, assuming that the fallure of one coil will shut down the reactor, is

$$
\mathrm{P}_{\mathrm{F}}=\mathrm{NP}_{1} \text { failures/operating reactor year }
$$

where $\mathrm{N}$ is the number of TF coils in the reactor. The reactor availability (percentage of time that the reactor operates) is then

$$
\mathrm{P}_{\mathrm{A}}=\frac{1}{1+\mathrm{NP}_{1} \mathrm{t}_{\mathrm{R}}}
$$

where $t_{R}$ is the TF coil replacement time in years. If the IF coil cannot be replaced and the reactor must be permanently scrapped, $t_{R}$ is taken as 30 years, the normal expected life of the plant. In practice, a replacement reactor could be built in 10 years, but this would reflect an extra capital cost. In order to compare the rests of plant non-availability on a common basis, the plants are assumed to be built at a normal interval of 30 ycuru. A plant availability of $80 \%$ is considered good for present power plants, both fission and fossil. Not all the down-time can be allotted to TF coil replacement in a fusion reactor, however, since other scheduled and nonscheduled replacement and maintenance operations will undoubtedly be necessary. Blankets w11l have to be replated, beam and vacuum lines maintained, etc., and failure of non-fusion reactor components will also contribute to reactor down-time. As a minimum, a plant availability of 0.95 is required considering only TF coil replacement. For an overa11 
plant avallability of 0.8 , this would correspond to $25 \%$ of the shut down time being a result of replacement operations on TF coils.

Figure 2.2 shows plant availability as a function of $P_{1}$, individual coll fallure probability, for the case of $N=18$ coils and the three replacement scenarios: $t_{R}=30$ years (non-replacement); $t_{R}=3$ years (replacement of a failed TF coil); $t_{R}=1$ month (replacement of a failed portion in a segmented TF coil with demountable joints).

To achieve the desired plant availability of $95 \%$, the allowable failure probability rate must be $\sim 10^{-4} / \mathrm{TF}$ coil year if the coil cannot be replaced, but could be almost 3 orders of magnitude greater if a segment could be replaced in 1 month. The achlevement of coil fallure rates of $10^{-4} /$ year could be very difficult. It would also require many reactor years of operation to estabifsh meaningful statistics on failure rates and obtaining this data could tend to retard rapid implementation of fusion reactors.

TF coil systems can be designed to permit replacement of entire coils. For example, each of the UWMAK-I TF coils (2) were removable along with their corresponding blanket and shield assembly and there were 12 such modules in the reactor. However, such design approaches tend to result in very massive modular sections for the reactor and require poloidal field windings outside the TF coils of very large current capacity. In addition, massive amounts of inter-coil support structure would have to be moved, joints between modules would have to be cut and remade. The time required for these operations could be quite long.

A more promising approach appears to be a demountable TF cofl with a number of joints in it: The TF coil assembly can then be designed so that if a portion of a TF coil falls, only the failed portion need be removed, without 
the necessity of moving other reactor components. There can be a variety of approaches to a demountable TF coil. The approach described in this report appears to be a very attractive one, but another approach may ultimately prove better.

A segmented rectangular TF coil (Figure 2.3) has several significant advantages"over a segmented curved coil:

1. Ease of segment manufacturing and shipping.

2. Ease of removal and insertion of both failed and new segments (only a straight pullout or insertion of a segment is required).

3. Use of massive conductors and insulators is readily accommodated (joining and disjoining is easier if relatively few turns are used).

In order to use a rectangular TF coil, however, the coil must be externally supported at a number of points to avoid excessive bending stresses if the amount of coll-structure is to be reasonable. The best support scheme appears to be the warm reinforcement approach (3) proposed In an earliex study where the supports go from the cold (4K) coil to a maceive ronm temperature reinforcement structure. 'l'he reftlgeration power required for the supports can be kept relatively small by using high strength materials with low thermal conductivity (stainless steel and epoxyfiberglass), and by using intermediate temperature heat sinks, e.g., $20^{\circ}$ and $80^{\circ}$ Kelvin, in the supports. As shown later in this repurt, the refrigeration power resulting from heat leaks in the aupports is a small fraction of the total refrigeration power for the TF coil assembly. The largest heat leak is associated with the power leads. 
By having the reinforcement structure at room temperature, the cost of the reinforcement can be substantially reduced. In fact, the study on warm reinforcement ${ }^{(3)}$. Indicated that the savings in reinforcement cost were greater than the cost of the extra refrigeration due to the external supports. These savings were achieved even though the stress in the warm reinforcement magnet design was much smaller than in the conventional design. Thus, it appears quite possible that the DEALS (Demountable Externally Anchored Low Stress) magnet can combine demountable capability with low stress in the conductor (on the order of a few thousand psi) and still be cheaper than a conventionally wound $D$-shaped magnet in which the reinforcement structure is at $4 \mathrm{~K}$ and the conductor/refnforcement are under much higher stress.

Rather than constructing a separate warm reinforcement structure specifically for the magnet assembly, as was assumed in the earlier study, it appears much more desirable to use the primary containment structure around the reactor as the warm reinforcement. The primary containment will be required in any event to contain activation products, etc., in the event of an accident. In general, it will be a relatively thick structure of reinforced concrete, on the order of several meters thick, resembling to a considerable degree the PCRV (Prestressed Concrete Reactor Vessel) for HTGR's. Serving as the warm reinforcement structure for the magnet, and coilialning activation products in the event of accidents, the PCRV type structure will also function as a biological shield. Externally supporting the magnet conductor with a massive PCRV will also make the probability of missile generation from magnet disruption vanishingly small: In effect, a magnet break could not result in any part of the magnet being acceleratcd to high velocities. 
Figure 2.3 shows the joints of the segmented TF coil to be located at the corners of the coil. This construction is discussed in more detail in a later section. The joints are formed by soldering conductors that meet at a $90^{\circ}$ angle. Other possible joint patterns are discussed later. Figure 2.4 illustrates the removal procedure for the three types of segments (inside vertical, top or bottom, outside vertical), with the joints located at the corners of the coil. To remove a top or bottom failed segment, 2 joints have to be unmade at the ends of the failed segment. The failed segment is thon mover slighcly up, if it id at the tnp nf the coil, or down, if it is at the bottom, to clear the vertical segments of the coil, and then pulled out through an opening in the PCRV. The appropriate warm reinforcement supports can be retracted to permit the failed segment to move up or down Into a shallow slot in the PCRV so that it can clear the vertical segments (these slots are not. shown in the idealized illustration in figure 2.3.). A 1.5 meter deep slot is probably sufficient to permit the withdrawn segment to olear the rest of the magnet. The outside vertical leg can be withdrawn by a similar procedure, with two disjoints at the outer corners of the coil. Kemoval of lle inside vertical leg is sumewhat morc involved, Three disjoints would be necessary, and the top horizontal leg would have to be retracted slightly to permit the inside vertical leg to be withdrawn. An alternate way of removal with two disjoints requires the movement of the rest of the cuil radinlly outward hy tracks designed for this purpose to clear the passage for the inner leg. Another possibility involving the removal of a portion of the buiking cylludei and inward radial movement of the inner leg before upward withdrawal is mentioned in a later section.

The removal procedure can be somewhat simplified by using different type of foints, and such possibilities are discussed later in this report. 
The procedure outlined above seems relatively straightforward, however, and should not require more than a few days to carry out.

An example of a DEALS design for a UWMAK-II size reactor is developed in this report. Tables 2.1 and 2.2 summarize the magnet and structural $\varphi^{\prime}$ parameters and Figure 2.5 illustrates the scale of the TF coil. The rectangular DEALS coil is sized to have the same overall dimensions as the D-shaped UWMAK-II coil as shown in Figures 2.5 and 2.6. Smaller size DEALS coils could be used, however, and any of the reactor designs could accommodate a DEALS magnet system, including the ANL, GA, and ORNL EPR designs.

The UWMAK-II size DEALS magnet design is discussed in more detail later in the report. However, the principal design feature requirements. and advantages of DEALS can be summarized and evaluated:

- Relatively high conductor currents are desirable to minimize number of joints.

- Rigid, plate type conductors are desirable to minimize stress. at joints.

- Conductors are contained inside a rigid case which also serves as the helium container.

- Materials are selected to keep conductor bundle rigid after cool down.

- External supports arc movalle to accommodate thermal contraction of the DEALS coil.

- Refrigeration requirements are larger than those for a conventional D type coil, principally because of larger lead heat leaks, but are still quite reasonable.

- Using external supports reduces the stress in the conductor by a significant amount, as compared to a conventional $\mathrm{D}$ coil and also reduces the amount of expensive cold reinforcement required in the coil. 
TABLE 2.1 DEALS MAGNET PARAMETERS

[UWMAK-II SIZE]

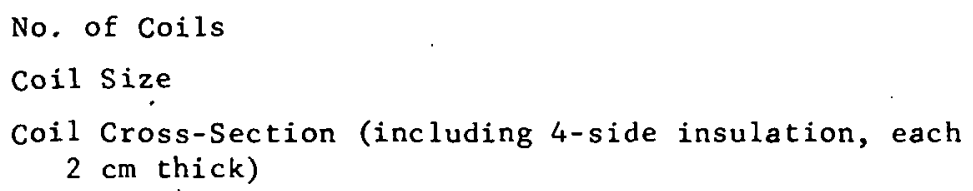

No. of Turns Per Coil

$0.785 \mathrm{~m} \times 1.04 \mathrm{~m}$

Condurtor Sizes (SC and Copper)

50

SC Sizes* (NbTi)

Insulator Sizes **

(1) $0.01 \mathrm{~m} \times 1 \mathrm{~m} \times 30 \mathrm{~m}$

(2) $0.01 \mathrm{~m} \times 1 \mathrm{~m} \times 20 \mathrm{~m}$

(1) $0.001 \mathrm{~m} \times 1 \mathrm{~m} \times 30 \mathrm{~m}$

(2) $0.001 \mathrm{~m} \times 1 \mathrm{~m} \times 20 \mathrm{~m}$

(1) $0.005 \mathrm{~m} \times 1 \mathrm{~m} \times 30 \mathrm{~m}$

(2) $0.005 \mathrm{~m} \times 1 \mathrm{~m} \times 20 \mathrm{~m}$

Peak Field at Conductor ( $(25.75 \mathrm{~m}$ )

8.35 Tesla

Field at Plasma Center (@13.0m)

3.69 Tesla

Operating Current

Amp-Turns Per Coil

Total Amp-Turns

Average Current Density Over Conductor

Average Current Density Over Coil

Reyuircd Hoat Transfer Rate When All Current Flows in Copper Stabilizer

$2 \times 10^{5}$ amps

$10^{\prime}$

$2.4 \times 10^{8}$

$2000 \mathrm{~A} / \mathrm{cm}^{2}$

$1300 \mathrm{~A} / \mathrm{cm}^{2}$

0.2 watt $/ \mathrm{cm}^{2}$

Inductance Per Coil

$\sim 0.33$ henry

Total Indirtance

$\sim 7.9$ henry

Stured litcriby Por Coil

Total Stored Energy

Average Pulsed Field Rate Over TF coil

Rise Time (or down-time)

$6.6 \times 10^{9}$ joules

Plasma Burn Time

$1.58 \times 10^{11}$ jülé

$0.5 \mathrm{Tesla} / \mathrm{sec}$.

1 second

Esliwated Heat Leaks (Eddy current, power lead, coil

case supports, etc.)-Rm. temp. power requlrement.

$1000 \mathrm{sec}$ onds

Estimatcd Refrigeration Requirement-Rm. temp. power requirement

$16.62 \mathrm{Mw}$

rotul Gimituctor Length Per Coil

$20 \mathrm{Mw}$

Total Conductor Volume Per Coil

$4800 \mathrm{~m}$

in $\mathrm{m}^{3}$

*SC cross-section calculated for highest field of 8.35 Tesla

**Approximate dimensions 
TABLE 2.2 DEALS STRUCTURAL PARAMETERS

[UWMAK-II SIZE]

Coil Case Thickness

Centrai Column Thickness

Stresses in Coils and Supports

Horizontal Legs

No. of Intermediate Supports

Max. Stress in Steel Case

Max. Stress in Conductor

Max. Stress in Supports

Outside Vertical Leg

No. of Intermediate. Supports

Max. Stress in Steel Case

Max. Stress in Conductor

Max. Stress in Supports

Inside Vertical Leg

Continuous Support Along Entire Length

Max. Stress in Steel Case

Max. Stress in Conductor

Max. Stress in Support

$50 \%$ of Length Supported

Max. Stress in Steel Case

Max. Stress in Conductor

Mex. Stress in Supports
11

5 in.

$19.7 \mathrm{in}$

10

$14 \mathrm{ksi}$

$10 \mathrm{ksi}$

$31 \mathrm{ksi}$

$12 \mathrm{ksi}$

$6 \mathrm{ksi}$

$14 \mathrm{ksi}$

$8.3 \times 10_{7}^{7} \mathrm{~N} / \mathrm{m}_{2}^{2}$ $4.1 \times 107 \mathrm{~N} / \mathrm{m}^{2}$

$6 \mathrm{ksi}$

$4 \mathrm{ksi}$

$6 \mathrm{ks} \mathrm{i}$

$9 \mathrm{ksi}$

$5 \mathrm{ksi}$

$11 \mathrm{ksi}$
$9.6 \times 10_{7}^{7} \mathrm{~N} / \mathrm{m}_{2}^{2}$

$6.9 \times 10_{8} \mathrm{~N} / \mathrm{m}_{2}$
$50 \mathrm{~cm}$. 
- Coll segments can be manufactured and pre-tested at a central factory location that could service many fusion reactors, and then shipped to the reactor site. Field fabrication requirements are minimal compared to those for conventionally wound coils.

- Insulators can be thick, rigid plates. This permits the use of ceramic insulators Instead of organic insulators, which eliminates problems of radiolytic $\mathrm{H}_{2}$ release and insulator degradation. Use of alumina permits insulators to have high thermal conductivity, which greatly reduces temperature inhomogeneities during quench situations.

- Conductors can be fabricated and assembled in shapes that minimize eddy current losses due to pulsed fields.

- Grading of superconductors to accommodate changing fields is relatively easy.

- Brittle superconductors can be readily used since strain is minimized and conductors do not have to be wound when the coil is assembled. Also, superconductors fabricated by sputtering, vapor deposition, etc., techniques can be used.

Thnngh the primary mulive for proposing DEALS is the capability of rapid repair in the event of fallure, the advantages of much lower stress, less cold reinforcement, much less fleld fabrication, capability of using thick ceramic insulators, and ability to more readily use high field superconductors are very important.

- The need for relatively high nnductur currents in DEALE, on the order of $\sim 10^{5}$ amps, may appear to be a disadvantage as compared to the conductor currents of $\sim 10^{4}$ amps that have been postulated for the TF magnets in fusion 
reactor reference designs. It should be pointed out that the DEALS conductors should be relatively easy to manufacture, and the relatively low coil inductance of a DEALS TF coll permits the major portion of the magnetic energy to be dumped externally in a quench or accident situation. With a conductor current of $\sim 10^{4}$ amps, as postulated in most reactor reference designs, the magnetic energy will have to be primarily dumped in the TF coil conductor and structure instead of externally, unless the coil is subdivided into a large number of independent circuits which have separate leads and external dump resistors.

The DEALS approach could in principal also be applied to the superconducting $\mathrm{OH}, \mathrm{VF}$, and divertor coils in Tokamak reactors. These possibilities have not been inves,tigated in any detail, however. The DEALS concept would seem to be readily applicable to DC divertor coils, but might not be feasible for $\mathrm{OH}$ colls where the current and fields are pulsed on a relatively fast time scale, i.e., seconds. For such applications, the conductor must be subdivided to keep AC losses reasonable, and the joining of conductor segments might be too difficult. However, it should be noted that there are approaches that do not require that the superconductor be finely subdivided. Instead, as in the magnet design for the MIT collisional Tokamak reactor concept, ${ }^{(4)}$ ali pulsed fields can be produced by non-superconducting coils. The superconducting poloidal field coils in this design are DC, located outside of the plasma, and serve as the vertical field coils during the plasma burn. The $\mathrm{OH}$ pulse is provided by a set of fast nulling poloidal coils which use normal conductors. These null out the field from the DC superconducting colls at the start of the burn. There is no set of coils, either superconducting or normal, inside the throat of the Tokamak. 
The DEALS magnet concept can also be applied to non-Tokamak superconducting magnet systems. One important application might be for Yin-Yang magnets. It will probably be difficult to wind the very large multi-axis coils required for a mirror fusion reactor. The Yin-Yang magnets could be built from a small number of joined straight segments; however, with the segments manufactured at the factory and shipped to the reactor site for assembly. The helical. windings on a stellarator could also be built from prefabricated segments.

The DEALS concept has broader implications for Tokamak reactors than just a cheaper, more relfable TF magnet system. Three important improvements can be made in conjunction with the Tokamak confinement approach to maximize access, minimize down-time, Improve reliability, and reduce total reactor cost. These all occur as a result of being able to build $\mathrm{TF}$ colls in shapes that would not be possible with conventional winding methods. The DEALS TF coll need not be planar, and can be much longer than their width.

Considering the first improvement, the outer legs of the TF coils can be made non-planar to maximize both end and radial access to the Tokamak blanket and shield. Figure 2.7 shows one possible configuration for this maximum access approach, using nominal $18 \mathrm{TF}$ coils. The number of TF coils could be more or less than 18, if desired. This arrangement should permit much more flexibility in arranging penetrations involved for beam lines, vacuum lines, holes for removing blanket segments, etc. The required shielding for magnets in the viclnity of penetrations appears to be considerably easier with the more flexible magnet arrangement. This arrangement is similar to an approach proposed by $\mathrm{GA}^{(5)}$, but the GA coils were not demountable.

The planes of most of the conductors in the upper and lower horizontal legs of the DEALS TF colls now lie at an angle with respect to the plane of 
the poloidal field. As a result, the eddy current loss will increase substantially, since the heights of the conductors are approximately two orders of magnitude larger than their widths. Nevertheless, the eddy current loss is a relatively small fraction of the total refrigeration loss in the design example discussed later in this report, a substantial increase in eddy current loss is possible without serious penalty. In addition, the upper and lower legs of the DEALS TF coils can be placed at a considerabe height above or below the poloidal field coils, so that the pulsed fields are relatively small. In fact; the upper and lower horizontal legs of the DEALS coils could be located near the outer surface of the PCRV, which would then maximize access to the demountable joints. (These options are discussed in more detail later.) Such a placement would greatly reduce the pulsed fields at the horizontal legs. Finally, eddy current heating in the legs due to. pulsed fields could be greatly reduced by using either a superconductor or normal metal shield.

The second improvement to the Tokamak is potentially more important than the first, and involves more of a departure from existing reactor concepts. Access to the blanket for replacement or repair operations would be dramatically improved if the reactor could be split on its midplane and the upper and lower halves moved apart. Such a procedure has been propnsed for the mirror fusion reactor, ${ }^{(6)}$ where the two coils of a Yin-Yang coil set can be separated by vertically raising the upper coll and exposing the spherical blanket for maximum access.

Such a splitting of the Tokamak reactor could be readily carried out If the TF coils had sufficient vertical clearance to permit the reactor halves to move apart. This would dictate very large conventional $D$-shaped 
TF coils to obtain a $\sim 5 \mathrm{~m}$ separation. The vertical clearance necessary to fully separate the reactor halves would require moving the outer edge of the TF coil radially outwards by an amount comparable to the separation.

Figure 2.8 shows an elevation view of a Tokamak with DEALS TF coils in which the upper and lower reactor halves are separated. The flexibility in shape with DEALS colis permits large vertfcal clearance with minimum increase in overall volume of the Tokamak reactor.

The poloidal coils, vacuum lines, and beam ports attached to each reactor half can remain in place. In practice, it probably would be easier to have the upper reactor half fixed in place and drop the lower half, which could be on a movable hydraulic or other type of support. The services to the lower reactor half, i.e., the current leads to the lower poloidal coils, as well as the beam and vacuum line joints, would have to be disconnected before the lower half of the reactor could move downwards.

The large separation would permit a remote maintenance machine to operate from outside the reactor to easily reach in and rapidly remove all portions of the blanket. With a minimum activity blanket, the radiation dose inside the separated halves of the blanket would only be a few $\mathrm{r} /$ hour, permitting limited direct maintenance in case of unexpected problems. When the minimum activity blanket sections had been removed, it would be possible to directly work inside the separated halves installing the new blanket since the exposure level would be very low, on the order of $\mathrm{mr} /$ hour. This would have very important benefits in terms of reactor down time, since it probably will be much faster to remotely strip out used blanket sections than to replace them. The time advantage for direct operations, which can be an order of magnitude faster than remote operations, can then be gained on the more difficult step on installing new blanket sections. 
A number of blanket arrangements are possible that would be compatible with this rapid access concept. In general, header pipes should probably be placed at the midplane of the reactor for the sections covering the inboard and outboard surfaces of the blanket wall. The header lines for the sections on the outboard wall could exit radially outwards through the shield and the header lines for the sections on the inboard wall could exit vertically (both upwards and downwards) inside the inboard.shield. The header lines for both the top and bottom surfaces of the blanket could exit vertically through their respective adjacent shields. Vacuum seals could be made on the midplane of the outboard shield at its outer rim after the two halves of the reactor have been brought together. Similarly, the seals for the inboard shield could be made at the top and bottom after the halves have been assembled.

This concept, which we term MAXAMAK (Maximum Access Tokamak) can use a similar arrangement of non-planar $T F$ coils to maximize radial and end access to the reactor. The degree of access required would have to be determined by a conceptual design. The remote handling equipment will probably require an opening several meters across which should be readily achievable.

The third improvement possible for Tokamaks using DEALS magnets is a further step beyond the MAXAMAK concept. Besides difficulty of access, conventional Tokamaks generally do not use space efficiently, which is costly, and also require an elaborate, expensive system to smooth out power swings when the plasma burn stops.

One possible way to mitigate these problems is the MULTIMAK approach (Figure 2.9). Several plasma chambers can be arranged to use the same 
DEALS TF coil system. The operating cycle can be chosen so that the same number of chambers is always operating on the plasma burn portion of the cycle. With 3 chambers, for example, the plasma exhaust phase for each chamber would take one-third of total cycle time for the chamber. The reactor output would be steady with time and equal to the total of two chambers.

In Figure 2.9, the MULTMAK is turned so that its toroidal axis is horizontal. This should make no difference to the operation of the Tokamak plasma, and should be substantially cheaper than designs in which the toroidal axis is vertical. The latter approach requires a much taller, larger volume containment building. However, use of underground rock containment and magnet system reinforcement is an alternate possibility for the vertical reactor orientation.

The MULTIMAK could have any number of plasma chambers, but 3 would appear to be close to an optimum. A much larger number of chambers cuuld result in too large an electrical capacity for a given TF coil system, considering that a single component failure, e.g., the TF coil system, should not knock out too much generating capaclty. Also, blanket replacement will probably require discharging the $\mathrm{TF}$ coil (though it can remain at $4 \mathrm{~K})$, before replacement operations begin. Since the plasma chambers will not be able to operate when the $T F$ coil is discharged, it appears very desirable to replace all blankets at the same t1me. The replacenent operations on each plasma chamber can probably be carried out in parallel. This may or may not require duplication of remote handling machines, depending on what operations are to be carried out and their time requirements, phasing, and the amount of direct maintenance that is feasible.

The MULTIMAK example shown in Figure 2.9. assumes similar plasma 
dimensions and magnetic fields to those developed in the MIT high density Tokamak design. (4). The maximum magnetic field is 14.7 Tesla, which would require $\mathrm{Nb}_{3} \mathrm{Sn}$ conductor. As mentioned earlier, the low conductor stress during operation, as well as the elimination of strain resulting from conventional coil winding methods, should make the DEALS approach very attractive for high fleld designs such as the above.

The central column which could be stainless steel or aluminum at $4 \mathrm{~K}$ will still have no net magnetic force, but will have to be supported against its own weight. Such supports could be placed between plasma chambers. Bending stresses appear to be small, since the unsupported length/diameter ratio is relatively small, about $3 / 1$.

Similar MULTIMAK illustrations could be shown incorporating other plasma chamber designs. For example, a MULTIMAK of slightly larger oyerall size could accommodate three doublet type, DEMO size plasmas, ${ }^{(7)}$ and would only require $\mathrm{NbTi}\left(\mathrm{B}_{\max } \approx 8\right.$ Tesla) in the DEALS magnet system. The total MULTIMAK reactor power generation with three such plasma chambers ( 2 burning, 1 pumping) would be comparable to that using the MIT type plasmas, i.e., $2000 \mathrm{MW}(\mathrm{e})$.

The movable halves of the plasma chambers could be mounted on a track and separation of the reactor halves would appear to be relatively simple. Rather than removal into a cask outside the reactor, the used blanket segments could be dropped down a disposal chute that would be uncovered when the reactor halves were separated. At the bottom of the chute, the segments could be guillotined into small sections or shredded, and then transported to storage for ultimate disposal.

Other MULTIMAK designs are possible. One interesting variant is to make a current loop instead of a toroidal field magnet. The DEALS current 
loop could be constructed from four straight segments, for example, with demountable points at the corners. At the center of each straight segment, the azimuthal magnetic field would approximate a $1 / \mathrm{R}$ field, and would be essentially the same as a toroidal field if the segment is long. Tokamak plasma chambers could then be constructed around each of the four current segments. As in the other design approaches, the reactors could be split at their midplanes so that the halves could be separated for maximum access to the blanket.

The principal advantages of this äproach are Increased access (end and return TF conductors would be eliminated) and somewhat simpler magnet constructions. The disadvantages are the relatively large size of the current loop, large fringe magnetic fields, and the need for auxiliary coils around the plasma chamber to compensate for non $1 / R$ field effects associated with the other sides of the current loop.

Finally, another potential application for the DEALS magnet system is the construction of non-planar TF coils for Tokamaks. If suitably twisted out of plane, magnetic shear can be produced in the coroldal fleld, which would eliminate the need for plasma current. In effect, this confinement approach is similar to the stellarator, except that magnetic shear is produced by the twist in TF coils, instead of by helical windings. It would be very difficult to construct such colls by conventional winding methods, and the stresses would probably be very large. With the DEALS approach, however, the twisted coils would be easier to construct and the stresses much lower. This confinement approach would be very appealing if it is feasible, since pulsed field coils and power supplies could be eliminated. The rest of this report examines a particular example of the DEALS magnet system, as applied to a UWMAK-II type reactor. 


\section{DEALS COIL DESIGN FOR UWMAK-II SIZE REACTOR}

\subsection{Conductor Mechanica1 Arrangement}

Basica11y, the finished conductor is a long copper plate with length, $l$ width $w$, and thickness $t$. This TF magnet system is sized similar to that for the UWMAK-II ${ }^{(8)}$ type power reactor. The conductor lengths are 20 meters and 30 meters to form a $20 \mathrm{~m} \times 30 \mathrm{~m}$ rectangular coil. For this design exercise, we take the width of the conductor to be 1.0 meter and the thickness 0.01 meter. (The design example has not been optimized and further work may change some dimensions.) A typical section and cross-sections of the conductor are shown in Figure 3.1. Three different types of conductor design are considered in this study. Figure 3.1 (a) shows the cross-section of the conductor with transposed braid superconductor sandwiched between copper plates; $3.1(\mathrm{~b})$ shows the conductor with graded rectangular superconductor wires; and 3.1 (c) shows the conductor with graded round superconductor wires. [Probably, the same size wire will be used because of the conductor end machining for the joint (see next section.) Grading can be accomplished by spacing. Conductor wires can be more densely packed in the higher field region, and less packed in lower field region. It should be noted that superconductors can also be graded differently for each independent coil segment to achieve optimized design.] The wires shown in (b) and (c) are commercially available. The transposed braid is in the advanced development stage. BNL has been using this type of superconductors for Isabelle magnet windings. The conductor was made by BNL. It is assumed that the technology of transposed braid type superconductor is well in hand for advanced conductor design. Figure 3.1(d) shows a three-dimensional view of a section of the proposed conductors. Helium cooling passages are also shown on both surfaces of the copper plate. 


\subsection{Conductor Fabrication}

The conductor is designed to be fabricated using present technology and machinery. Figures $3.2,3.3$, and 3.4 show. the steps of conductor fabrication. The diagrams in these figures are self-explanatory.

The advantages of the scheme can be listed.below.

(a) Each piece of the conductor is machined to the specified size to conform to the desired design tolerance.

(b) A large number of identical conductors permit computer controlled machining and handling.

(c) Because of the conductors short length, individual pieces of conductor with defects can be discarded or refabricated, unlike the conventional rolls of continuous wire conductor which have to be scrapped because of a defective section or sections.

\section{3 Coil Fabrication}

The special feature of this magnet system is that unlike other superconducting coils, there is no coil winding process involved. Each coil section or its component is prefabricated in the factory, and the only operation required on site is the joining and welding process. 'Iransportation of the coll segments from factory to reactor site is now possible with present railroad or truck systems.

Figure 3.5 shows two cardboard models of coil segments. The models show. several conductor plates and insulations. The inner coil case serves the purposes of containing the coil and helium. The fabrication process of coil sections should be simple and eas1ly mass-produced, since the operacion cunsists of stacking the prefabricated-conductors and insulation plates and then welding the case. 


\subsection{Coil Segment Joining and Disjoining Operation}

(a) Joining Operation

Figure 3.6 and 3.7 illustrates the simple joining action in which the following steps are taken:

(1) Engage the end together as shown in Figure 3.6.

(2) Insert the heater plate and clamp the joint as shown in Figure 3.7. The heater is powered until the pretinned surfaces are soldered.

(3) Heater is turned off with clamp on.

(4) Heater and clamp are removed when the joint is cooled off and insulations are inserted as shown in Figure 3.8. The joining operation is complete.

(b) Disjoining Operation

The disjoining process is the reverse of the above, with the following steps:

(1) Remove the insulation.

(2) Insert heater plates.

(3) Clamp the joint and power the heater.

(4) Remove clamp at proper temperature and slowly disengage the coil joints while keeping heater on. This completes the disjoining action.

The joining and disjoining operation of the coil case, $80 \mathrm{~K}$ radiation shield, super-insulations, and vacuum dewars are all standard present day techniques and will not be described in this report.

\subsection{Cooling Methods}

The cooling channels of the conductor are designed to provide 50 percent cooling area for each surface as illustrated in Figure 3.1. The required heat 
transfer rate when the total current flows in the copper can be estimated as follows: Total resistance per unit length of conductors ( $1 \mathrm{~m} \times 1 \mathrm{~m} \times 0.01 \mathrm{~m})$, taking the average resistivity to be $5 \times 10^{-10} \Omega \mathrm{m}$, is $5 \times 10^{-8} \Omega$. Therefore, the total heat generated is

$$
I^{2} R=\left(2 \times 10^{5}\right)^{2} \times 5 \times 10^{-8}=2000 \text { watt. }
$$

which gives the estimated heat transfer rate requirement to be approximately

$$
\frac{2000 \text { watt }}{100 \mathrm{~cm} \times 100 \mathrm{~cm}}=0.2 \mathrm{watt} / \mathrm{cm}^{2}
$$

This is well below the $0.4 \mathrm{watt} / \mathrm{cm}^{2}$ criterion normally used to assure cryostatic stability.

In this study, both pool cooling and force cooling methods are considered, and Figure 3.9 and 3.10 illustrate the ideas of each type of cooling.

(a) Pool Cooling Option

The cooling channels of the conductor, indicated in a typical section of the vertical coil segment shown in Figure $3.9(\mathrm{c})$, are designed to be short such that the longest distance a helium bubble has to travel is no more than 1 meter long before it is channeled through holes in the insulating plate, shown in Figure $3.9(b)$, to the much larger helium channcls on the inside wall of the coil case shown in Figure $3.9(8)$. Also shown in the same figure is the auxiliary cooling and warm-up channels designed into the magnet coil case and an electrical warm-up circuit. The function of this system is to assure a uniform cool-down or warm-up process of the coil case to avoid thermally induced stress problems. The coil itself and the inner surface of the coil case will be cooled down or warmed up traditionally by circulating helium gas through the refrigerator. In addition, the electrical heating circuit built into the coil case and the 
conductor (see instrumentation under operational safety) will help for a faster warm-up if needed.

(b) Force Cooling Option

The force cooled helium passages are shown schematically in Figure 3.10 where helium enters at the top of the coil and exists from the bottom. Each individual cooling channel is about 50 meters long around one-half of the coil perimeter. The cool-down and warm-up design of the coil and the coil case is the same as described in the pool cooling method. Design details of both cooling methods will be presented in a future report.

\subsection{Insulation}

If organic insulators are used in superconducting coils for fusion reactors, - radiation damage may be of considerable concern. The special feature of the straight coil segments in this design allows the possibility of using ceramic insulators which would be more durable in a neutron flux environment. This is. because the insulation pieces in this design are all flat plates, as shown in Figure 3.9 and 3.10. The grooves and windows appear to be well within the present day capability of ceramic fabrication. An important point is that only compression will be felt by these insulators, and there should not be any significant tensile or bending stress on these ceramic plates.

\subsection{Operational Safety}

\section{(a) Instrumentation}

Probes, heaters, etc. can be embedded in the plate conductor during conductor fabrication. If the normal region detection probe in each individual conductor plate is monitored separately, there would be 200 probes per TF coil. If they are electrically connected at the corners and each turn of the conductor is monitored separately, then there will only be fifty probes per TF coil. 
However, if it is necessary to have redundant detection circuits, then considerably more than fifty detection circuits per coil will be required. The heaters can be connected together at the corners to form a single heater for a temperature equilization system of the entire coil. Other probes such as thermometers or strain gauges can also be easily installed during conductor fabrication for cool-down, warm-up, and coil performance monitoring.

(b) Thermal Equalization Capability

The utilization of ceramic insulation (the total conductivity of $\mathrm{Al}_{2} \mathrm{O}_{3}$, for example, is orders of magnitude better than epoxy fiberglass or phenolic spacers) in this magnet design greatly increases the transverse thermal conductivity of the coil. The turns of the conductor are thermally coupled much better with $\mathrm{Al}_{2} \mathrm{O}_{3}$ insulation than is the case with the organic insulation. Heat generated by normal regions can thus spread to the adjacent conductors through the ceramic insulation reducing temperature gradients in the event of a quench. In addition, the above described temperature equalization system in the conductor, can drive the entire coil normal if a quench occurs.

\section{(c) Energy Removal}

The inductance of each coll is approximately 0.33 henrys, which is much lower than any previous supericonducting coll design of comparable size aud lield. This results in short charging and discharging times and fast energy removal capability during a quench. The following example illustrates how rapidly energy can be removed. Assuming $2000 \mathrm{~V}$ as an allowable voltage across coil leads during a quench, an external 10 milliohm shunt would remove the stored magnetic energy. The $L / R$ time conetant will then be

$$
\frac{L}{R}=\frac{0.33}{10 \times 10^{-3}}=33 \text { seconds . }
$$


The room temperature dielectric strength of $\mathrm{Al}_{2} \mathrm{O}_{3}$ is $200 \mathrm{kV} / \mathrm{cm}$. The insulation thickness between conductor layers in this design is $0.5 \mathrm{~cm}$ and approximately $2 \mathrm{~cm}$ thick between coil and ground; hence, it should be capable of withstanding a much higher voltage than $2000 \mathrm{~V}$, which would result in an even shorter energy removal time.

\subsection{Advanced Options}

The relatively short, flat conductor plates and low stress of this coil design allow one to readily use an advanced superconductor such as $\mathrm{Nb}_{3} \mathrm{Sn}$. The flat conductor can also serve as a substrate to employ advanced superconductors which have to be made by evaporation, sputtering or other methods $\left(\mathrm{Nb}_{3} \mathrm{Al}, \mathrm{Nb}_{3} \mathrm{Ge}\right.$, etc.). Very high field capabilities can be achieved by utilizing the brittle high-critical field conductors with this conductor design and coil support method. Also, cupernickel may be used to laminate the copper stabilizer to further reduce the AC losses.

4. DEWAR DESIGN

The dewar system consists of the inner dewar which contains the coil and liquid helium, the $80 \mathrm{~K}$ radiation shields, and the outer dewar. A schematic diagram of the cross-section of the dewar system is shown in Figure 4.1. One of the coil case supports is also shown to illustrate how the magnet coil is supported and the thermal contraction problem accommodated. The support system will be described in more detail in a later section.

This dewar vacuum system contains superinsulations separated by one $80 \mathrm{~K}$ radiation shield. The radiation shield and the outer dewar wall can be welded onto the framework built around the coil case, and these vacuum walls are not designed to bear any forces. The magnet transmits its load through the support sustem to the hydraulic supports external to the dewar. 
Also, Figure 4.1. does not represent the dewar cross-section of all the coil segments. The case for the top coil segment in the pool-cooling case, for example, will probably be designed differently to include helium gas space. However, detailed dewar design will not be discussed in this report.

5. CRYOGENIC REQUIREMENT

5.1 Heating Input

(a) Eddy Current Loss

The similarity between this coil conductor arrangement configuration and the transformer core lamination greatly reduces the matrix AC losses due to pulsed poloidal fields. The lamination in this coil design is made parallel to to the direction of the pulsed field in contrast to most coil designs to date where the wider surface of the conductor has to be wound perpendicular to the direction of the field. M. N. Wilson's ${ }^{(9)}$ formula for a conductor slab of thickness 2 a parallel to the field pulse was used to estimate the losses.

$$
Q=\frac{2(\Delta B)^{2} a^{2}}{\pi^{2} p t}\left(\text { joules } / \mathrm{m}^{3}\right)
$$

where $a=0.005 \mathrm{~m}$ in the present conductor design; $\Delta B$ is chosen to be $0.5 \mathrm{Tesla}$; $\rho$ is the resistivity and $i t s$ average value is around $5 \times 10^{-10} .52-\mathrm{m} ; t$. is the rise time of 1 second. The burn cycle for a power reactor can be set at 1000 second, however 100 second burn time is also included for comparison.

$$
Q=\frac{2 \times(0.5)^{2} \times(0.005)^{2}}{\pi^{2} \times 5 \times 10^{-10} \times 1} \simeq 2.5 \times 10^{3} \text { joules } / \mathrm{m}^{3}
$$

Loss per meter length can be computed from the above number to be 25 joules. Since the total length of conductor per coil is 4800 meters, the loss is $1.2 \times 10^{5}$ joules. Thus, power loss per coll is given by

$$
\begin{aligned}
& 1000 \text { second burn time: } P_{\text {Loss }}=0.12 \mathrm{Kw} \\
& 100 \text { second burn time: } P_{\text {Los }}=1.2 \mathrm{Kw}
\end{aligned}
$$


Total power loss of this design of 24 coils amounts to $2.88 \mathrm{Kw}$ and $28.8 \mathrm{Kw}$ for two different burn cycles. It should be noted that this computation does not include the shielding effect which could reduce the losses another factor of 10 as suggested by ANL's EPR design.

There are also eddy current losses in the coil case, but this term will not be considered in the present study. Knowing that the resistivity of stainless steel is several orders of magnitude higher than copper, the coil case's contribution to the losses should not cause any concern at this stage of study.

(b) Hysteresis Loss in Superconductor

This calculation was made on a thin sheet of superconductor of $1 \mathrm{~mm}$ thick and 1 meter wide, with the surface of the superconductor parallel to the pulsed field as shown in Figure 3.1(a). The following formula from M. N. Wilson's work ${ }^{2}$ was used for this estimate.

$$
\begin{aligned}
& Q=\frac{\Delta B^{2}}{2 \mu_{0}} \frac{\beta}{12}\left(\text { joules } / \mathrm{m}^{3}\right) \text { for } \beta<2 \\
& Q=\frac{\Delta B^{2}}{2 \mu_{0}}\left(\frac{1}{\beta}-\frac{4}{3 B^{2}}\right)\left(\text { joules } / m^{3}\right) \text { for } \beta Z^{2}
\end{aligned}
$$

where $\beta=\frac{\Delta B}{\mu_{0} J_{c}{ }^{2}}$, and $2 a$ is the thickness of the superconductor sheet. The above two equations were plotted in Figure 5.1, and the maximum of $Q / Q_{0}$ was used to compute the hysteresis losses, where $Q_{0}=\Delta B^{2} / 2 \mu_{0}$. Hence,

$$
Q=\frac{(0.5)^{2}}{2 \times 4 \times 10^{-7}} \times 0.187=1.86 \times 10^{4} \text { joules } / \mathrm{m}^{3}
$$

The total amount of superconductor per coil is $4800 \times 1 \times 0.001=4.8 \mathrm{~m}^{3}$, therefore, the loss per coil is $8.9 \times 10^{4}$ joules. The total power losses during two different burn cycles of $1000 \mathrm{sec}$, and $100 \mathrm{sec}$. are approximately $2.16 \mathrm{Kw}$ and $21.6 \mathrm{Kw}$ respectively. 


\section{(c) Losses From Conductor Joints}

Assume that the copper thickness between the superconductor at the joint is $2 \mathrm{~mm}$ thick. The resistance of a $2 \mathrm{~mm}$ thick resistive region of the area $1.0 \mathrm{~m} \times 1.0 \mathrm{~m}$ is given by

$$
R=\rho \frac{L}{A}=5 \times 10^{-10} \Omega-m \times \frac{0.002}{1 \times 1}=10^{-12} \Omega
$$

The loss per joint is therefore,

$$
I^{2} R=\left(2 \times 10^{5}\right)^{2} \times 10^{-12}:=4 \times 10^{-2} \text { watt }
$$

And the loss per coil is

$$
200 \times 4 \times 10^{-2}=8 \text { watt }
$$

which results in 192 watt of total loss. There are films of solder between the joint and between the superconducting braid and the copper stabilizer; however, their total thickness is less than a tenth of a millimeter thick and their contribution to the losses is negligible.

(d) Power Lead Loss

The heat load through the gas-cooled leads is by far the largest loss in this design because of the high magnet current. Accurdiug lu tlie powei lead analysis by General Electric Co., the loss is linearly proportional to the current carried and is $3.0 \times 10^{-3}$ liter/hour ampere/pair. (11) Therefore, a set of twenty-four pairs of leads carrying 200,000 amps would reauire 14 Mw of electrical power during operation to run a He liquefier or refrigerator. In actual practice, coils can be grouped together and connected in series to reduce the number of power leads required if desired. Hence, $14 \mathrm{Mw}(\mathrm{e})$ would be the maximum rooul teunperature power requirement for leads and thls power reouirement could readily be cut by a factor of 2 or 3 . In addition, the value of $3 \times 10^{-3} 1 /$ hour amp pair is quite conservative as compared with the optimized power lead calculations of Hi lal (12) (1nn\% of rarnot efficiency). He projects an ideal power requirement of $300 \mathrm{w}(\mathrm{e}) / \mathrm{KA}$ pair. With practical refrigerator efficiencies of $\sim 25 \%$, the input power required to overcome lead heat leaks would be only $5 \mathrm{Mw}(\mathrm{e})$. 


\section{(e) Losses From Instrumentation Penetration}

Assume 1000 copper wires $10 \mathrm{mils}$ in diameter and 1 meter long connecting the room temperature to the $4 \mathrm{~K}$ region, the heat leaks can be estimated as follows

$$
Q=k \frac{A x \Delta T}{L}
$$

where $A \sim 0.5 \mathrm{~cm}^{2} ; \mathrm{L}=100 \mathrm{~cm} ; \Delta \mathrm{T}=300 ;$ and $\mathrm{k}$ was chosen at 5 watt $/ \mathrm{K}-\mathrm{cm}$. Therefore,

$$
Q=5 \times \frac{0.5 \times 300}{100}=7.5 \text { wat } t / \text { coil }
$$

and the total instrumentation loss is 180 watt

\section{(f) Coil Case Supports Loss}

One of the coil case supports is shown in Figure 4.1. Fifty such supports per coil were chosen for this estimate. Both in-plane and out-of-plane supports are assumed to be included in this number.

According to a previous report, ${ }^{(3)}$ a support of epoxy fiberglass and stainless steel laminate, half a square meter in area and $10 \mathrm{~cm}$ thick, can be designed for a 2 watt heat leak from a $20 \mathrm{~K}$ heat station to the $4 \mathrm{~K}$ coil case region. Hence, the heat leak per coil is 100 watt and the total heat leak is 100 watt $x 24=2.4 \mathrm{Kw}$. The loss from the $80 \mathrm{~K}$ to the $20 \mathrm{~K}$ heat station and from the $300 \mathrm{~K}$ to the $80 \mathrm{~K}$ heat station will not be discussed in this report.

Instead of using a separate $20 \mathrm{~K}$ hydrogen refrigerator and $80 \mathrm{~K}$ nitrogen refrigeratnr, it appẹns to be mope econouille lú use large hèlium retrigerators for all three temperature functions, as was pointed out in the report of warm reinforcement for fusion reactors.

\section{(g) Vacuum Loss}

The vacuum dewar is shown in Figure 4.1. The heat leaks from the $80 \mathrm{~K}$ radiation shield to the $5 \mathrm{~K}$ coil case can be estimated by assuming that the spacing between the coil case and the $80 \mathrm{~K}$ shield is $20 \mathrm{~cm}$ apart with superinsulation wrapping in the 
vacuum space. The combined heat transfer coefficient is taken conservatively as $0.7 \times 10^{-6}$ watt/K-cm from the 7 -foot bubble chamber design at BNL. ${ }^{(13)}$ Therefore, the loss per unit area is

$$
Q=\frac{\mathrm{A} X \Delta \mathrm{T}}{\mathrm{L}}=0.7 \times 10^{-6} \frac{100 \times 100 \times 75}{20}=2.6 \times 10^{-2} \text { watt } / \mathrm{m}^{2}
$$

The total coil case area of 24 magnets is approximately $10^{4} \mathrm{~m}^{2}$, which creates 260 watts of heat leak. Note that this calculation includes the areas which were taken up by the coil case support pads, whose heat leaks were already accounted for.

In conclusion, the estimated heat leaks are small enough that this design, with external warm supports, appears feasible. The estimates are summuriued in Table 5.1.

TABLE 5.1 LOSSES TO 5 K ENVTRONMENT

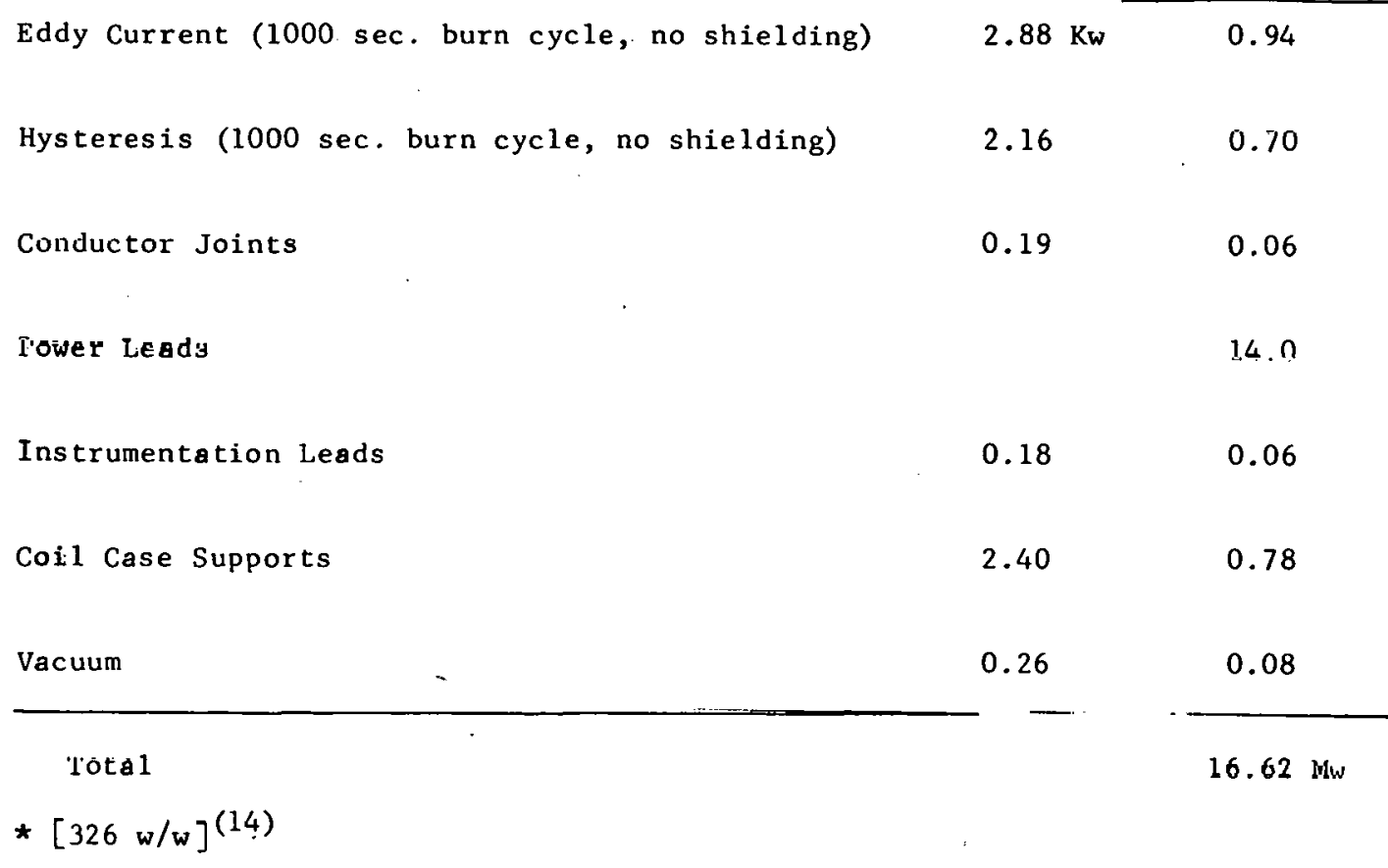




\subsection{Refrigeration Requirement}

The first two terms in Table 5.1 were overestimated. A proper shielding will cut those numbers by a factor of ten. ${ }^{3}$ The loss due to conductor joints was also overestimated since the copper thickness between the superconductors at the joint does not have to be $2 \mathrm{~mm}$ thick. The losses due to instrumentation leads and the vacuum are insignificant. The $2.4 \mathrm{Kw}$ heat leak from coil case supports was estimated using the best available data. Better support design might lower this value somewhat. The most important heat leak comes from power leads. However, larger heat leaks should be readily tolerated in a fusion reactor. For example, if one (1) percent of the electrical output from a $2000 \mathrm{MW}(\mathrm{e})$ reactor is used to power a refrigerator, with a refrigeration factor of 300 watts (e)/watt(th) $[4 \mathrm{~K}], 66 \mathrm{Kw}$ of heat leak at $4 \mathrm{~K}$ would be accommodated. The capital costs of this scale of refrigeration would be substantial, but they would still be a small fraction of the total plant cost. Thus, even if we were restricted to heat leaks corresponding to those achieved by present commercial leads, the refrigeration requirements would be acceptable.

In addition to the losses described in this study, there are other losses such as transfer lines, storage dewars, $20 \mathrm{~K}$ and $80 \mathrm{~K}$ heat station losses, "etc. that have not been estimated. However, these losses should not be significant, and we feel that $20 \mathrm{MW}(\mathrm{e})$ of refrigeration load will probably be realistic for this type of magnet design. The nuclear heating input is not considered here. 


\section{DEALS STRUCTURAL ANALYSIS FOR UWMAK-II SIZE REACTOR}

\section{1 Stresses and Strains in Coils}

(a) Magnetic Forces on Coils

For a DEALS magnet system comparable to UWMAK-II proportions as depicted in Figure 2.6, a field $B_{0}$ of 3.7 Tesla at 13 meters and $10^{7}$ amp turns per coil are required. For a rectangular coil of 30 meters by 20 meters and with the $\bar{I} \times \bar{B}$ force varying linearly through the coil thickness from a maxisium on the inside to zero on the outside, the following forces act on each leg of the rectangular coil:

$8.1 \times 10^{7}$ bs or $3.6 \times 10^{8} \mathrm{~N}$ on each $20 \mathrm{~m}$ horizontal leg

$2.8 \times 10^{8}$ bs or $1.2 \times 10^{9} \mathrm{~N}$ on the $30 \mathrm{~m}$ inside vertical leg

$6.0 \times 10^{7} 1 \mathrm{bs}$ or $2.7 \times 10^{8} \mathrm{~N}$ on the $30 \mathrm{~m}$ outside vertical leg

These in-plane forces are always perpendicular to the leg and acting away from the plasma center.

Since the corner joints are not designed to Lunsimit loads, the force each ruil. exerts on the central column is just the $2.8 \times 10^{8}$ lbs. or $1.2 \times 10^{\mathrm{g}} \mathrm{N}$ of the 1 nside 1 eǵ. With 24 coils the total force on the central column is therefore $6.7 \times 10^{9}$ lhs. or $2.9 \times 10^{10} \mathrm{~N}$.

(b) Preliminary Calculations

The rectangular geometry of the coil will lead to extremely high stresses if supported only against the center culumin or at the four cuskera. Simplc beam calculations, considering each leg as a beam with end supports only, show that with a $.75 \mathrm{~m} \times 1.0 \mathrm{~m}$ conductor cross-section, a $1.0 \mathrm{~m}$ thick steel coil case is needed to keep stresses below $60,000 \mathrm{psi}$ or $4.1 \times 10^{8} \mathrm{~N} / \mathrm{m}^{2}$. This is obviously an unworkable 
size case. For a more reasonable coil case thickness of $5 \mathrm{in}$. or $12.7 \mathrm{~cm}$, with only the ends of the legs in the rectangular coil supported, bending stresses will exceed $6 \times 10^{5}$ psi $\left(4.1 \times 10^{9} \mathrm{~N} / \mathrm{m}^{2}\right)$ on the horizontal legs. However, beam calculations also show that with two intermediate supports along the horizontal span, these stresses will only reach a maximum of $1.25 \times 10^{5}$ psi $\left(8.6 \times 10^{8} / \mathrm{m}^{2}\right)$. While this stress is still much too high, the indication is that a reasonable number of supports along the span will bring stresses down to acceptable levels and with a sufficient number of supports, stresses will be well below those of ungupported constant tension designs.

\section{(c) Computer Calculations}

(1) To develop a better understanding of the stress levels in the rectangular coil, under various support conditions, a plane linear elastic finite element code was used to investigate the problem. Because of the plane nature of the code, a unit thickness layer of the coil was modeled. In doing so, the stiffening effect of the coil case sides was neglected and only the support against bending given by the coil case top and bottom were taken into account making the model a conservative approximation.

Two sets of computer runs were made: Several calculations of the stresses in the entire coil under various support conditions were done. When a reasonable support scheme was established, a more detailed model of each of the legs was analyzed with the finite element corie:

With $\mathrm{Nb}_{3} \mathrm{Sn}$ as the superconductor, stresses in the copper stabilizer should be kept below 15,000 psi to avoid strains greater that 0.002 (2) Although these limits are not necessary for the MbTi superconductor used here, it would be desirable to prevent stresses from going above the copper yield point of 12,000 psi. The aim of the fullowing analysis was to keep stresses in the conductor-stabilizer we11 below the 12,000 psi level. A five-inch thick steel case was considered a reasonable structural reinforcement for the coil. 
(2) The whole rectangular coil was modeled using 1888 elements and 1185 nodes for one unit thickness. Elements modeling the copper and steel regions were given appropriate material properties. Grid size is shown in Figure 6.1. Supports were simulated by fixing the nodes on the outside of the steel coil case where support would be placed.

As expected, if a rectangular coil was only supported on the central column analogous to D-shaped magnets, stresses on the order of $7 \times 10^{5}$ psi $\left(4.8 \times 10^{9} \mathrm{~N} / \mathrm{m}^{2}\right)$ in the steel arose in the corners. Even if the four corners were clamped and the inner leg supported along the central column, stresses were still on the order of $6 \times 10^{5}$ psi $\left(4.1 \times 10^{9} \mathrm{~N} / \mathrm{m}^{2}\right)$, similar to the values found by the simple beam calculations.

A reasonable support scheme was found to be the following: Four corners of the coil kept in place by supports plus eleven supports eaually spaced along the 30 meter vertical legs. In addition, ten supports were used along each horizontal leg. These were not evenly spaced since the magnetic force varied along these legs and closer support spacing was used where the force was stronger. This scheme is within the heat loss estimates of Section $5.1(f)$ of this report.

With this support.configuration, stresses in the ctool coil sase scayed below 14,000 psi $\left(9.6 \times 10^{7} \mathrm{~N} \mathrm{~m}^{2}\right)$ while conduclui strcuues remainnd below $7,500 \mathrm{psi}\left(5.2 \times 10^{7} \mathrm{~N} / \mathrm{m}^{2}\right)$ everywhere except on the inner vertical leg at the support points themselves. Compressive stresses at these inner eleven supports became too high, i.e., 30,000 psi in the conductor. However, with a more continuous type of support along the central cylinder to distribute the centering force more evenly, these stresses were brought liotom 7,500 psi also.

(3) Since the above support system provided a very favorable stress calculation using the whole coil model, a more detailed analys is of each coil leg was performed using the finite element grid shown lin Figure 6.2. With supports in the same location as for the whole coil case, stresses in the 
outside vertical leg were about 15 percent higher in the steel, but about 20 percent lower in the copper with the detailed run. Such stress changes were consistent with the change in element size. Stresses in the high field regions of the horizontal legs were almost 40 percent higher in the detailed computer runs. The finite element calculations also showed that the bottom, i.e., inside of the coil case, was very lightly stressed. The most economic and efficient case, therefore, seems to be one with three relatively thin sides, about two inches thick and a heavier side, about five or six inches thick on the outside of the coil.

(d) Thermal Stresses

Since the entire coil and case will be operating at $4 \mathrm{~K}$, thermal stresses could occur due to the different thermal contractions of the materials in the coil. In cooling from room temperature to $4 \mathrm{~K}$ copper contracts about $.0034 \mathrm{in} / \mathrm{in}$ and 304 stainless steel about $.0030 \mathrm{in} / \mathrm{in}^{(15)}$ while the ceramic insulators contract on the order of $10^{-6} \mathrm{in} / \mathrm{in}$; and are, therefore, rigid compared to the copper and steel. In assembling the coil then, the ceramic insulators must be kept somewhat shorter than the copper conductor plates, leaving slight gaps which will be closed due to the copper shrinkage. These gaps are indicated in Figure 6.3. Differences in shrinkage between copper and steel through the coil cross-section can be alleviated by appropriate choice of thickness of the ceramic to compensate. However, different contractions along the length of a leg can give rise to thermal stresses. The rigidity of the ceramic is not a problem since the insulator can be put between the conductors in long parallelogram-shaped sections whose ends could slide over each other to compensate for the contraction in the steel and copper. Over the 30 meter length of a coil leg, however, the copper will try to contract 0.5 inches more than the 304SS. This means that tensile stresses in the copper (on the order of $7,000 \mathrm{psi}$ ) may cause the soldered joints at the coil corners to seperate and disrupt good electrical contact. Several solutions exist 
to overcome this problem: The conductors could be anchored to the coil in several locations along the span so that the ends of the legs see only a small part of the total contractions. Also, movement in the joints may be prevented by a non-metallic bolt arrangement to give mechanical strength to the soldered joints. Designing bellow sections into the steel case is another solution. A very desirable solution would be the use of a steel whose contraction more closely matches that of the conductor.

\subsection{Hydraulic Supports}

(a) Reason for Hydraulic Support

As elaborated in the previous section, large rectangular coils are only structurally feasible if supports along the span of the legs are provided to transmit the load from the coil to the support structure. A hydraulically controlled and adjustable system would provide reliable yet sensitive supports capable of transmitting high loadings. Hydraulics provide a means of lluving the oupport pards with uniform and controlled velocity while adjusting their bearing pressures with accuracy. The supports could be adjusted to compensate for the thermal shrinkage during cool-down and the centering effect when the currents start flowing through Llie coilo.

Individual hydraulic rams could be extended liom the wupport atructure to the laminated support pads carrying the coil case load through the dewars shown in Figure 4.1. While these individual rams would allow very accurate control, so meny individual hydraulic drives would increase the chance of failure of a support. A more reliable system would appear to be one where the laminated support: pads frum the coll cast are engaged by a massive beam running along the coil leg length with only a few hydraulic drives along its span (Figure 6.4) Such a system, while simpler and more reliable, would also take up more room and may restrict access to the coils to a greater degree. If the support structure surrounds a coil leg, hydraulic supports may also be considered for providing lateral stability against out-of-plane forces. 
(b) Stresses in Layered Supports

For purposes of analysis, the supports used in the stress analysis of

Section 6.1 were taken as 1 meter by 0.5 meter by 0.25 meter deep. Stress values quoted in 6.1 were calculated with the support points as absolutely rigid. Other calculations were made simulating the supports with finite elements with a stiffness of $10^{7}$ psi or $6.9 \times 10^{10} \mathrm{~N} / \mathrm{m}^{2}$. Actual support. pads would consist of alternate layers of epoxy-fiberglass and steel to reduce heat leak. With a $10^{7}$ psi support stiffness, maximum stresses in the outside vertical leg with eleven equally spaced supports as before are now 12,100 psi $\left(8.34 \times 10^{7} \mathrm{~N} / \mathrm{m}^{2}\right)$ in the steel and 6,000 psi $\left(4.14 \times 10^{7} \mathrm{~N} / \mathrm{m}^{2}\right)$ in the copper. The maximum stress in the support pad came to 14,300 psi $\left(9.86 \times 10^{7} \mathrm{~N} / \mathrm{m}^{2}\right)$ and in the copper they were $10,500 \mathrm{psi}\left(7.2 \times 10^{7} \mathrm{~N} / \mathrm{m}^{2}\right)$. In the high field region of the horizontal leg, stresses in the support pad were now 31,000 psi or $2.1 \times 10^{8} \mathrm{~N} / \mathrm{m}^{2}$.

\subsection{Support Structure - PCRV}

Since a thermonuclear reactor must be enclosed by a biological containment anyway, it would seem most practical as well as économical to combine the external support structure with the biological containment. An attractive way to fulfill both functions would appear to be the use of a Prestressed Concrete Reactor Vessel (PCRV) similar to those used in the U.S. and Europe as containments for certain types of fission reactors: The PCRV can provide the necessary biological shielding since ft can be made gas tight with the use of steel liners. Current PCRV technology uses both reinforcing as well as prestressing steel to provide structural integrity. Weight ratios in a typical PCRV are 50:1:2 for Concrete: Reinforcing Steel: Prestressing Steel. ${ }^{(16)}$ The amount of steel needed in a PCRV is cuite large and comparablle to the steel needed for an all steel structure if concrete were not used. (The steel structure would, of course, be thinner.) 
However, in the PCRV the steel is in smaller pieces,i.e., tendons and bands, and larger structures can be built using PCRV's than with steel only.

The many independent tendons and bands incorporated into the prestressing and reinforcing of the PCRV provide a desirable degree of redundancy. Moreover, ungrouted tendons as well as the anchor hardware are accessible for repair and replacement. Also, certain control areas can be left open in the PCRV itself to provide access for crack inspection.

Largest current PCRV designs call for internal cavities on the order of $5 \times 10^{5} \mathrm{ft}^{3}$ or $1.4 \times 10^{4} \mathrm{~m}^{3}$, about half the diameter needed for a UWMAK-II DEALS. In order to enclose a DEALS CTR of UWMAK-II size entirely in a single cavity PCRV, the internal volume must be on the order of $3 \times 10^{6} \mathrm{ft}^{3}$ or $8.5 \times 10^{4} \mathrm{~m}^{3}$. This is not a very great extrapolation. Moreover UWMAK-II is a very large design--future CTR designs will very likely be more compact. Also, the needed volume can be reduced by using multicavities, i.e., separate cavities for the outside leg of the coils. Finally, designs are possible where portions of the coils are actually outside the PCRV and are supported by tension cables as indicated in Figure 6.5.

\subsection{Central Column Design}

The central column or bucking column must withstand the pressure due to The centering force on the coils once the current and field come on. The column would most likely be made of steel, but a high strength aluminum is also a possibility. The entire column could be cooled down to liquid helium temperature, and kept cold, or the column could be at room temperature with heat stations between it and the coils. Keeping the central column at one of the heat station temperatures,i.e., liquid $\mathrm{H}_{2}$ or liquid $\mathrm{N}_{2}$ is also a possibility. $\Lambda$ cold column would make coil support and clearance problems easier since then the need for heat stations and dewar walls between coil and column would be eliminated. As indicated in Figure 6.6 with the conductor width considered for the DEALS design discussed 
here, clearance problems at the center column could become severe if separate. dewars had to be used.

If the central column is treated as a thick-walled cylinder with a net external pressure of about 4,500 psi, the following table indicates the maximum stress in the column versus wall thickness:

\begin{tabular}{l|c|c|c|c|c} 
thickness (cm) & 10 & 20 & 30 & 50 & 60 \\
\hline$\sigma$ maximum (ksi) & 226 & 116 & 77 & 47 & 40
\end{tabular}

In reality a solid cylinder would not be practical for many reasons, including weight, access, ease of removal, etc. One possibility would be interlocking rings to build up the column. However, from the viewpoint of ease of assembly and disassembly of the coils, interlocking longitudinal column segments would appear to be the most attractive. Some possible central column configurations are shown in Figure 6.7. If there is one longitudinal column segment keyed to each coil, the inner coil $\mathrm{leg}$ and column segment could be removed together in case of coil segment replacement.

Some stress calculations on the supports of the inner leg to the central column show that for a continuous support of stiffness $10^{7}$ psi ail along the inner leg (cold column), stresses are quite low: 5,800 psi $\left(4 \times 10^{7} \mathrm{~N} / \mathrm{m}^{2}\right)$ in the supporls aild the ytecl caco, and 3,90 n psi. $\left(2.7 \times 10^{7} \mathrm{n} / \mathrm{m}^{2}\right)$ in the copper. A possible support scheme wițh a warm central column is shown in Figure 6.8. The support pads taper and are perforated to reduce heat leak. With about 50 percent of the length of the support actually butting up against the central column stresses are found to be $10,300 \mathrm{psi}\left(7.1 \times 10^{7} \mathrm{~N} / \mathrm{m}^{2}\right)$ in the support, $9000 \mathrm{ps} 1$ $\left(6.2 \times 10^{7} \mathrm{~N} / \mathrm{m}^{2}\right)$ in the steel and $5,200 \mathrm{psi}\left(3.6 \times 10^{7} \mathrm{~N} / \mathrm{m}^{2}\right)$ in the copper. Thede 
numbers indicate that a more continuous central support alleviates the compressive stress problem indicated earlier when only eleven supports of half a meter length along the inner leg were used.

\subsection{Accident Conditions}

One of the primary virtues of the DEALS concept is the ease of replacement of coil segments in case of failures in the coils. These replacement schemes are discussed elsewhere. The only accident condition considered here is the failure of one or two of the hydraulic supports. As mentioned before, a support failure would be more likely to occur with individually driven supports.

During the finfte element computer calculations mentioned earliar, with eleven supports along the vertical leg and ten along the horizontal, various supports were removed to see what effect this would have on stress magnitudes in the coil. With one support missing in the high field region of the horizontal leg, stresses of $24,000 \mathrm{psi}\left(1.65 \times 10^{8} \mathrm{~N} / \mathrm{m}^{2}\right)$ were found in the steel and $15,000 \mathrm{psi}\left(1.0 \times 10^{8} \mathrm{~N} / \mathrm{m}^{2}\right)$ in the copper. If simultaneously another support along the horizontal leg failed in the lower field region, no further stress increase was noted. On the outoide vertical leg, with one or two non-adjacent supports missing. steel stresses wero found to be $20,000 \mathrm{psi}\left(1.4 \times 10^{8} \mathrm{~N} / \mathrm{m}^{2}\right)$ and $8,500 \mathrm{psi}\left(5.9 \times 10^{7} \mathrm{~N} / \mathrm{m}^{2}\right)$ in lhe copper.

6.6 Assembly and Disassembly Procedures

(a) Number of Joints and Ease of Removal

There is an obvious trade-off between the number of joints and the ease of removal of the individual legs; More joints make for ohortcr, liglilel, and more easily manipulated segments; but the joints are the weakest points of the roil. Four $90^{\circ}$ cnrner joiult would be the miulnum needed tor separate removal of each leg. As indicated in Figure 2.4, after a joint was disconnected, the leg to be removed would have to be backed up over a meter to clear the adjoining legs before being slid out sideways. This would mean the supports along the 
span must be capable of withdrawing more than a meter. Inside leg removal would necessitate removal of one of the horizontal legs also, as shown in Figure 2.4 , with the four-joint scheme. The joints shown in Figure 6.9 avoid this problem with the inside leg. Another scheme shown in Figure 6.10 uses more joints but avoids the need to back off the legs before sideways removal, in that a corner plug is removed first providing clearance for sliding the legs out.

(b) Other Support and Disassembly Procedures

As mentioned previously, the possibility exists of having portions of the coils extend outside of the support structure or PCRV. All or some sections of the horizontal legs or outside vertical legs may extend beyond the main portion of the PCRV and could be supported by sets of tension cables such as shown in Figure 6.5. Aside from reducing PCRV size, this would provide easy access to all portions of the eoll outside the PCRV. Rigidity of supports, both in-plane and laterally, would not be as great, of course.

Polygonal shapes, other than rectangular, could be made with more segments and joints. Coil shapes, such as that of Figure 6.11, if they can be properly supported, would provide compactness and yet easy replacement of segments. The present study, however, confines itself to rectangular coils of a size similar to the UWMAK-II D coils.

(c) Central Column and Inner Leg Removal Schemes

As indicated above, removal of the inner leg of a rectangular coil presents the most difficulties because of the lack of clearance space and the high forces acting there during normal operation. With the four $90^{\circ}$ corner joints shown in Figure 2.4, the inner leg can only be removed if one of the horizontal legs is removed first. With the kind of joints shown in Figure 6.9 the inner leg could be pulled out vertically directly if a portion of the inner shield came 
with it. On the other hand, if the central column were segmented so that each inner coil leg were keyed to one segment, a means of removing the inner leg and column segment together could be devised (Figure 6.12). This arrangement would be especially desirable for a continuous support arrangement with a cold bucking column. If fewer column segments are desirable, a suitable arrangement, such as indicated in Figure 6.13, could be found to back inwards the appropriate segment and then pull the inside leg inward and up and out. The least desirable solution would be to assume the inside leg to be irremovable and confine replacement to the other three legs. This should not be necessary since several of the methods described above should prove to be practical. 


\section{REFERENCES}

1. "Oak Ridge Tokamak Experimental Power Reactor Study Reference Design", ORNL, W-7405-Eng-26, 1975.

2. B. Badger, et. al., "A Wisconsin Toroidal Fusion Reactor Design", UWFDM-68, University of Wisconsin, November, 1973.

3. J. R. Powell and P. Bezler, "Warm Reinforcement and Cold Reinforcement Magnet Systems for Tokamak Fusion Power Reactors" BNL Report 17434, 1972.

4. D. R. Cohn, et. al., "A High Density, High Field Tokamak Demonstration Power Reactor" to be published in the Proceedings of the 2nd ANS Topical Meeting .

5. C. C. Baker, General Atomic, personal communication.

6. Lee, et. al., "Mirror Reactor Blankets", Proceedings of the MFE Blanket and Shield Workshop", Brookhaven National Laboratory, March 29 - April 2, 1976, PP. $484-489$.

7. "Conceptual Design Study of a Noncircular Tokamak Demonstration Fusion Power Reactor", GA-A13992 UC-20, General Atomic, November, 1976.

8. B. Badger, et. al., "A Conceptual Tokamak Power Reactor Design", UWFDM-112, University of Wisconsin, October, 1975.

9. M. N.Wilson, and Colin Walters, Rutherford Laboratory Report (RL-76-038), April 1976, United Kingdom.

10. W. M. Stacey, et. a1., "Tokamak Experimental Power Reactor Studies" ANL/CTR75-2, ANL., P. T.V-23.

11. "Conceptual Studies of Toroidal Field Magnets for the Tokamak Experimental Power Reactor", Final Report prepared by General Electric Company, November 1, 1976.

12. M。 A. Hilal, "Optimization of Current Leads for Superconducting Systems", 1976 Applied Superconductivity Conference, Stanford University, Stanford, California, 1976. 
13. W. J. Schneider, BNL, private communication.

14. T. R. Strobridge, "Cryogenic Refrigerators--An. Updated Survey" NBS Technical Note 655, 1974.

15. "Handbook on Materials for Superconducting Machinery", MCIC-HB-04, ARPA-NBS, November, 1974.

16. "Gas-Cooled Reactor Technology-3," USAEC, General Atomic, April 22-26, 1974. 




Figure 2.1. Oak Ridge EPR reference design (August 1975). 


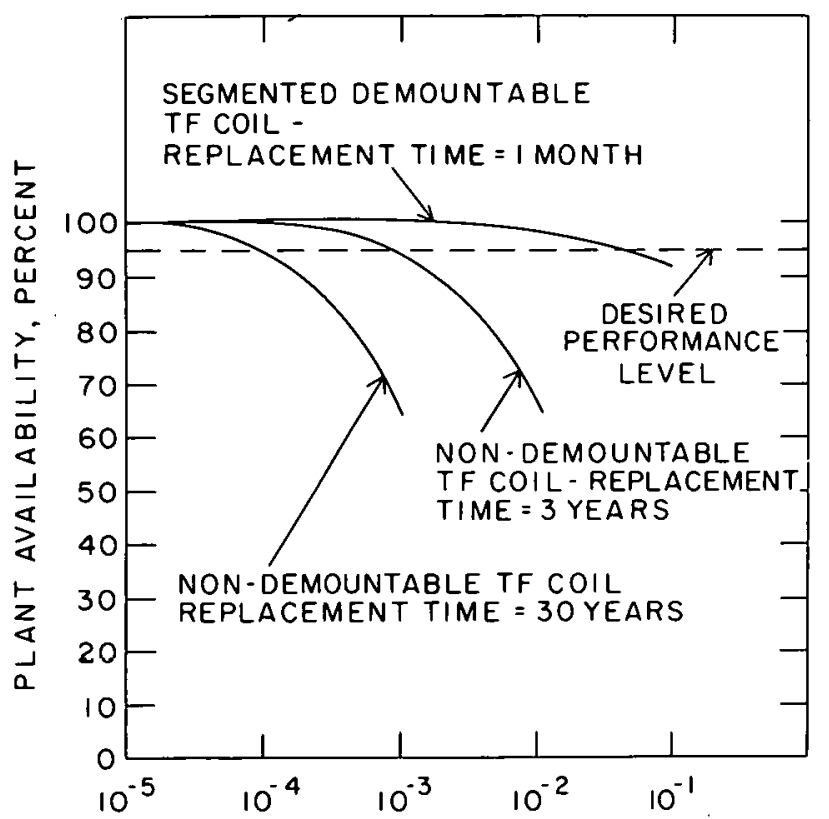

FAILURE PROBABILITY OF SINGLE TF COIL PER YEAR

Figure 2.2. Plant availability as a function of TF coil failure probability (down time due to other causes not included).

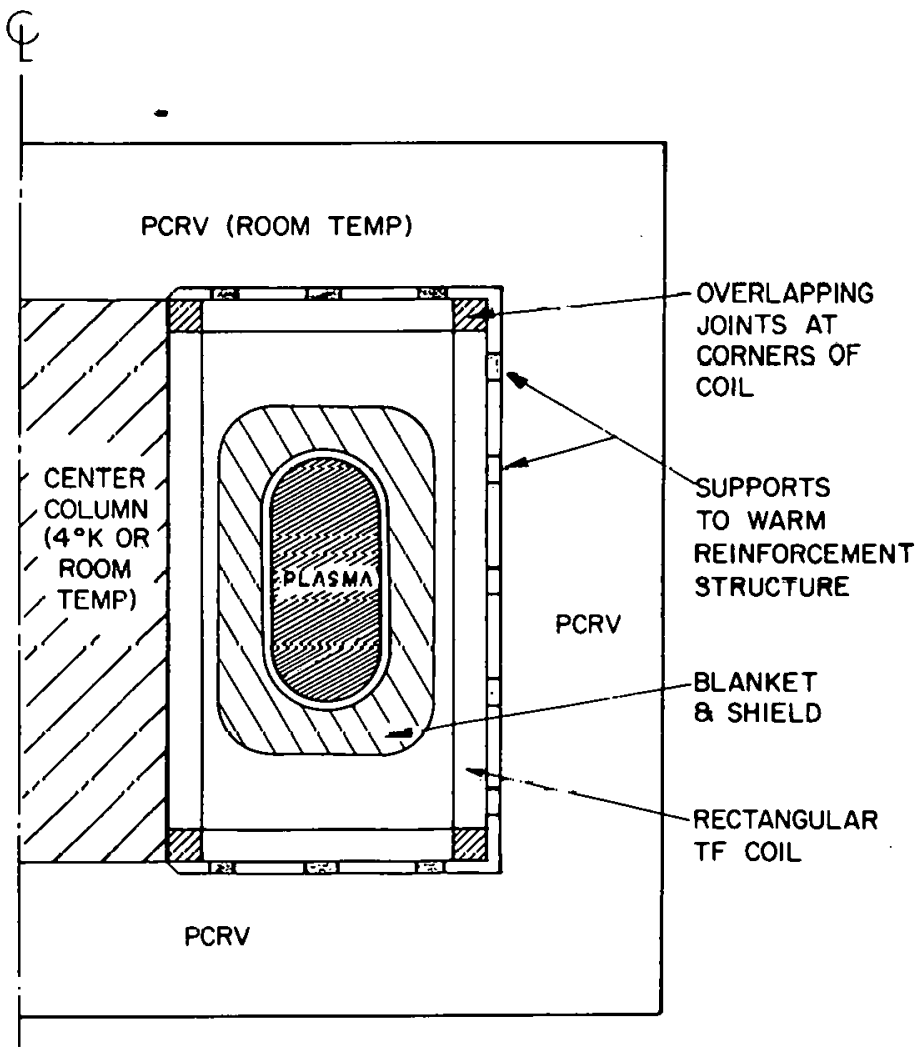

Figure 2.3. Schematic of arrangement of deals coils with PCRV reinforcement. 


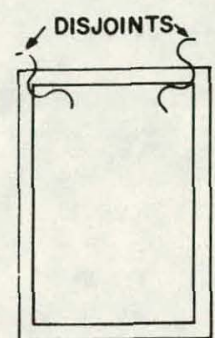

I.

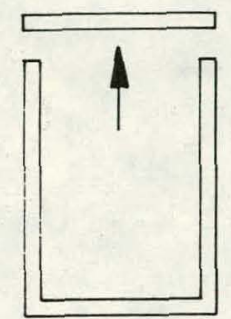

2.

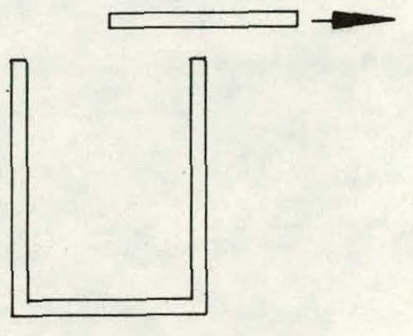

3.

REMOVAL OF TOP (OR BOTTOM) SECTION

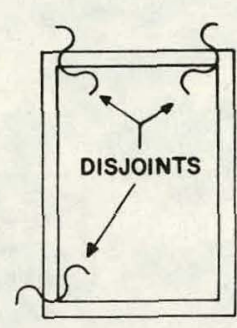

I.

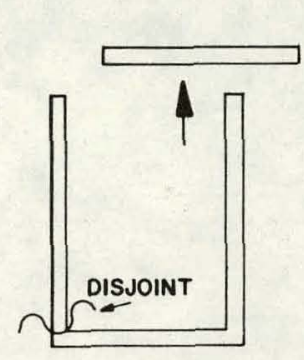

2.

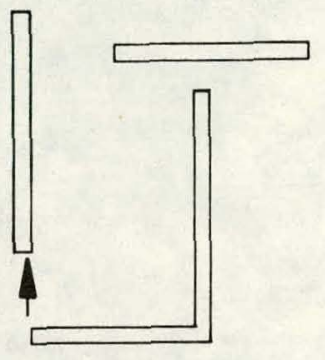

3.

REMOVAL OF INSIDE VERTICAL LEG

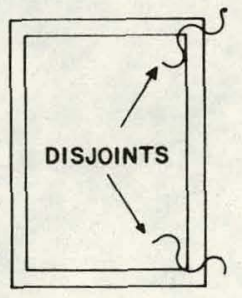

I.

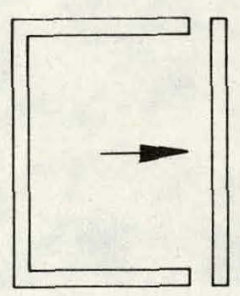

2.

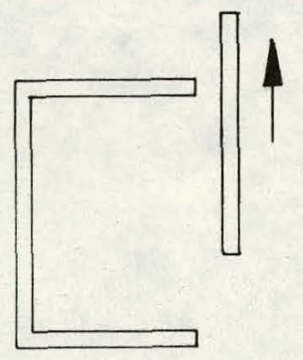

3.

REMOVAL OF OUTSIDE VERTICAL LEG

Figure 2.4. Removal procedure for failed section of deals TF coil (using $90^{\circ}$ corner joints). 


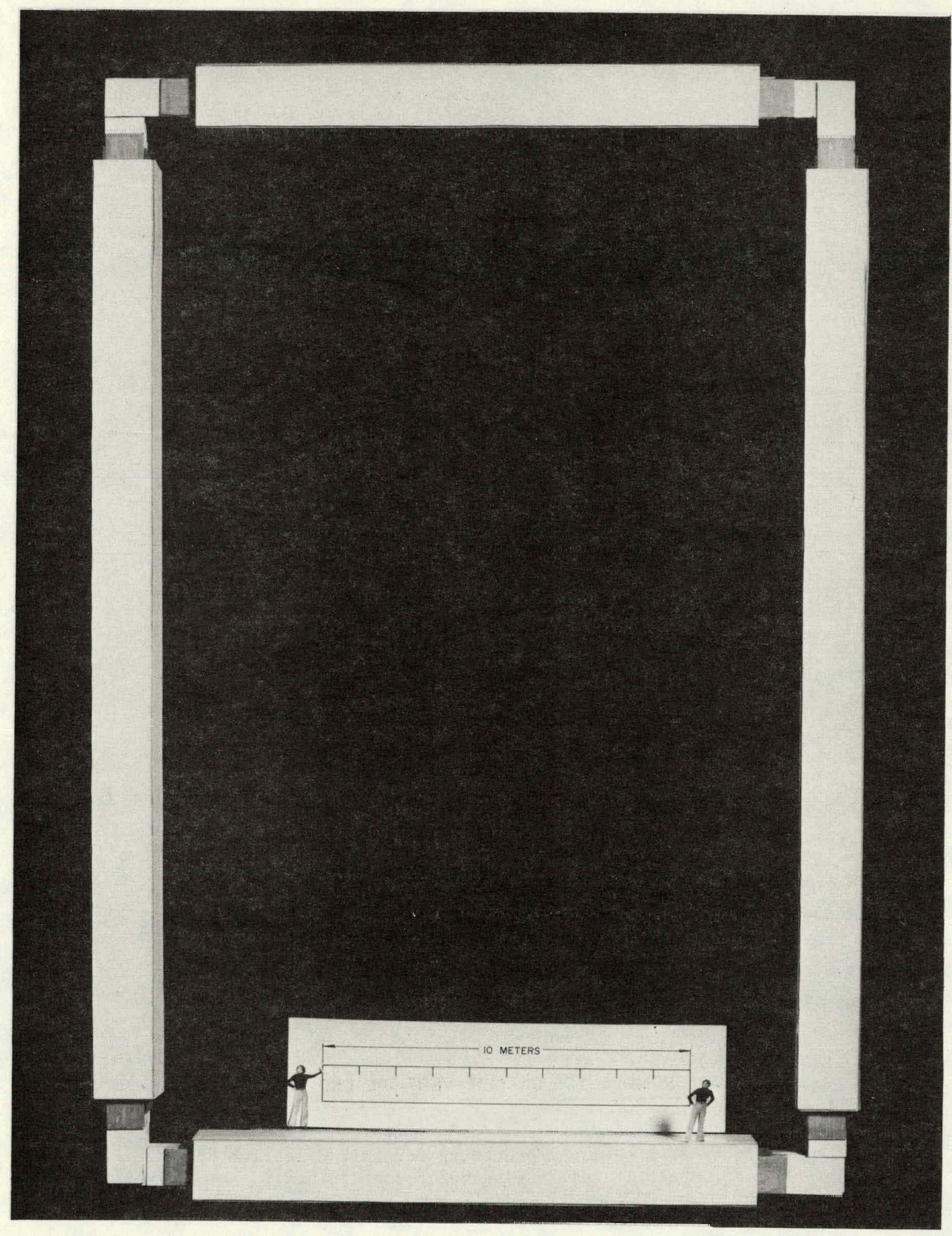

Figure 2.5. Model deals coil sized for UWMAK-II reactor design. 


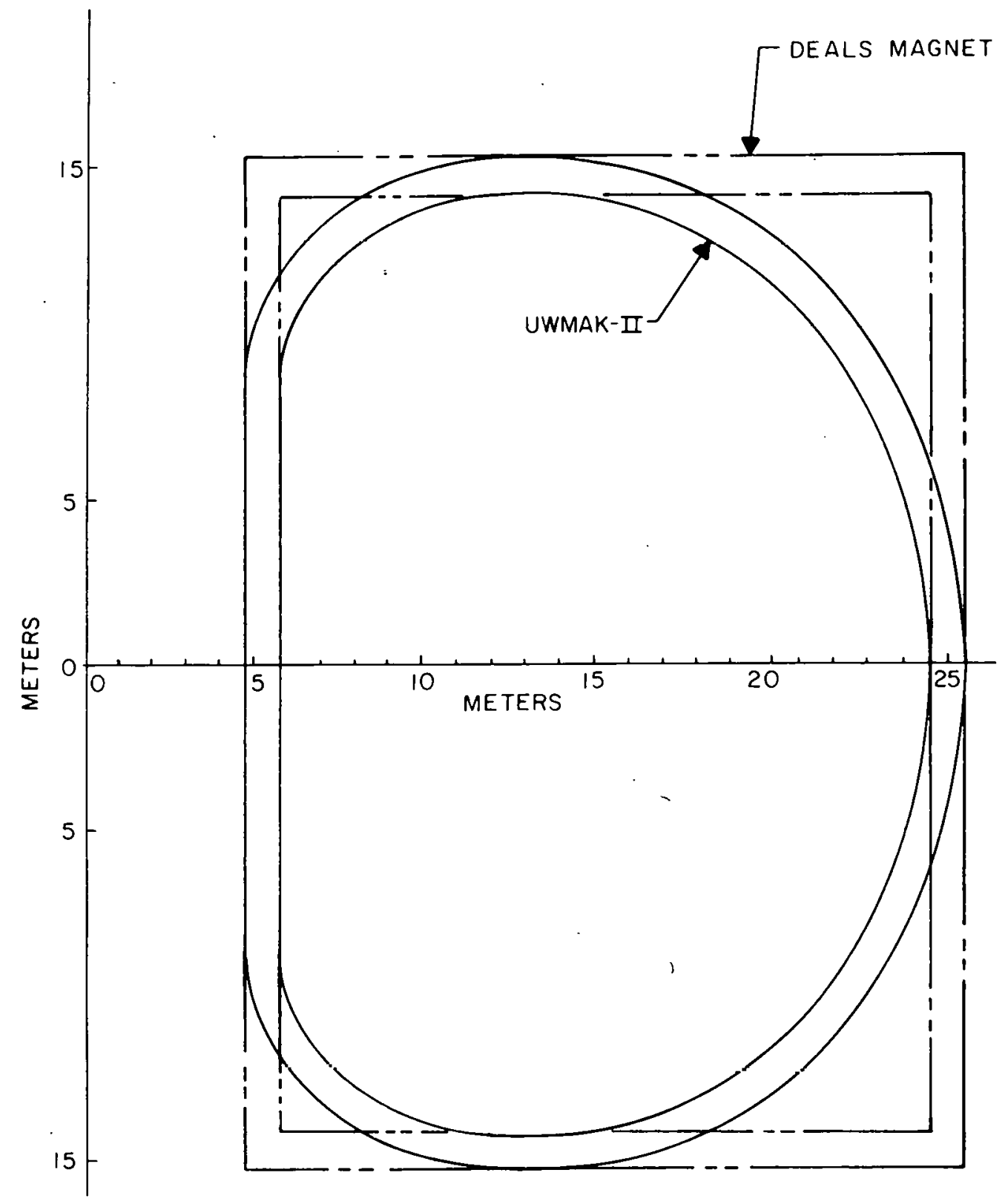

Figure 2.6. Comparative outlines for D-shape and deals TF coils for UWMAK-II fusion reactor. 


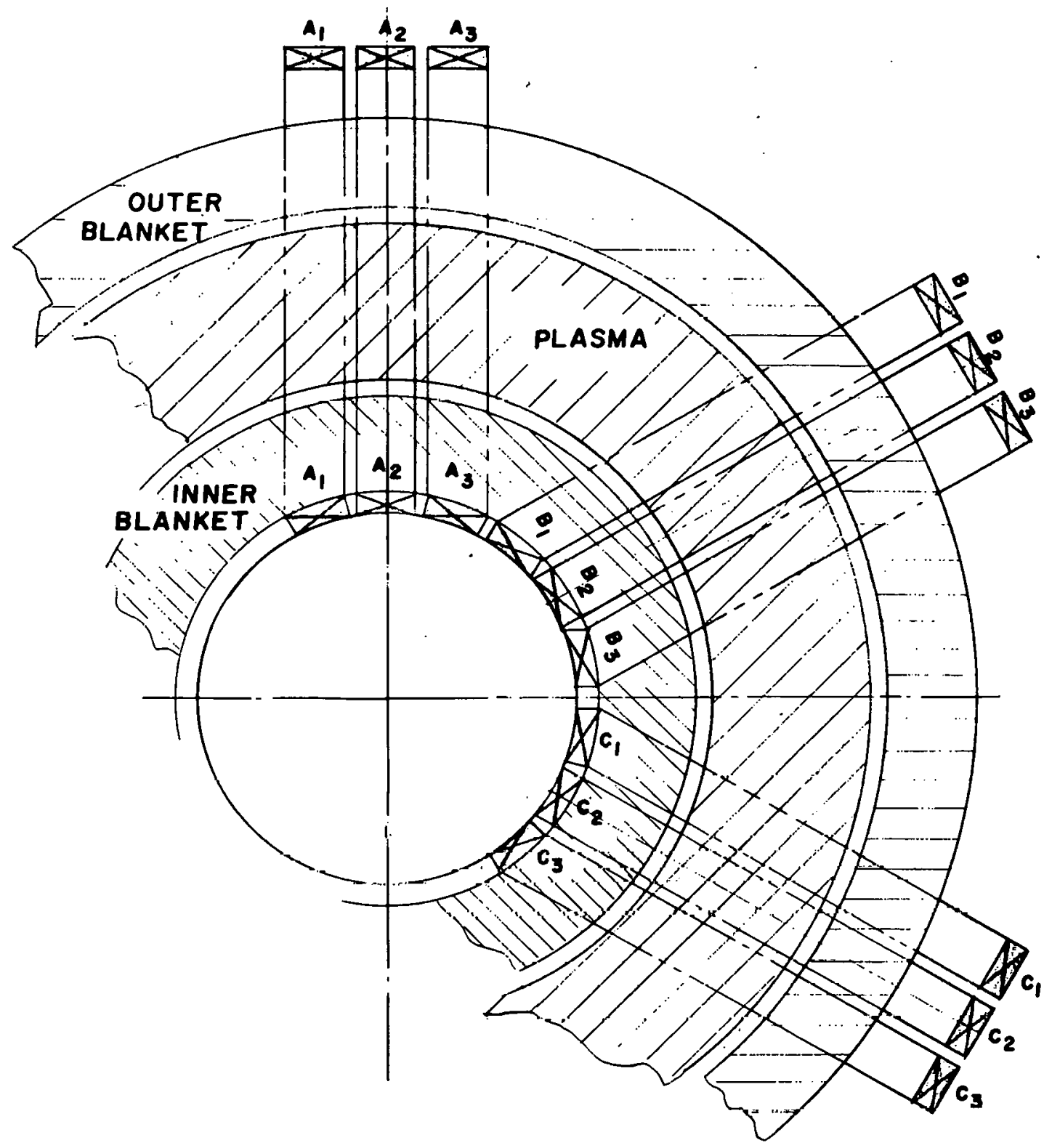

Figure 2.7. Non-planar arrangement of $\mathrm{TF}$ coils to maxlmfie radial and cind ácecoso. 


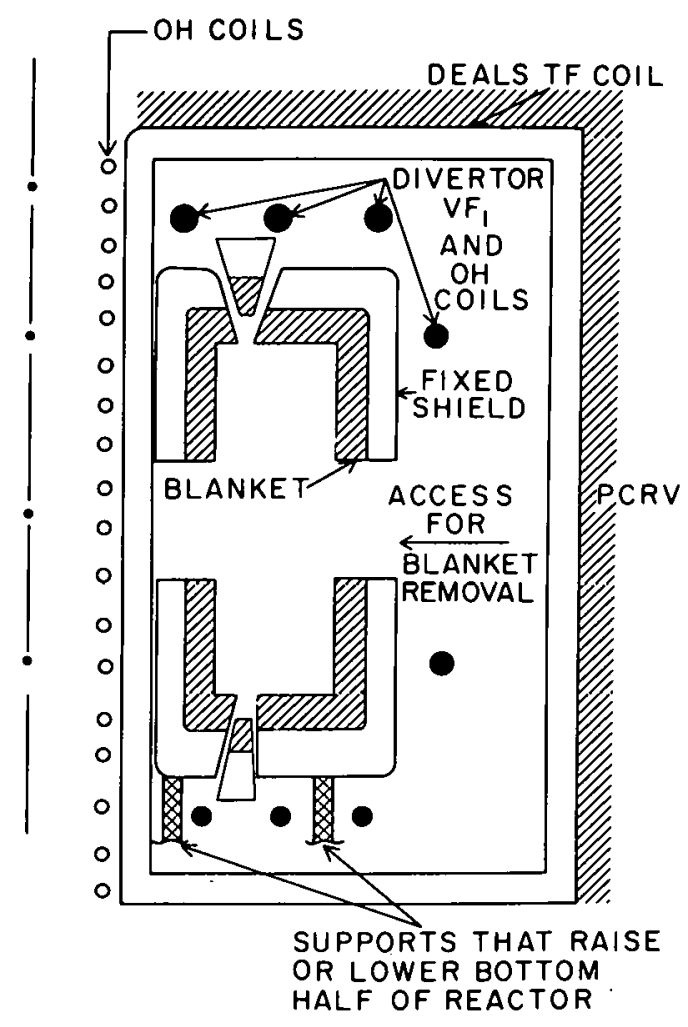

Figure 2.8. The maxamak (maximum access tokamak).

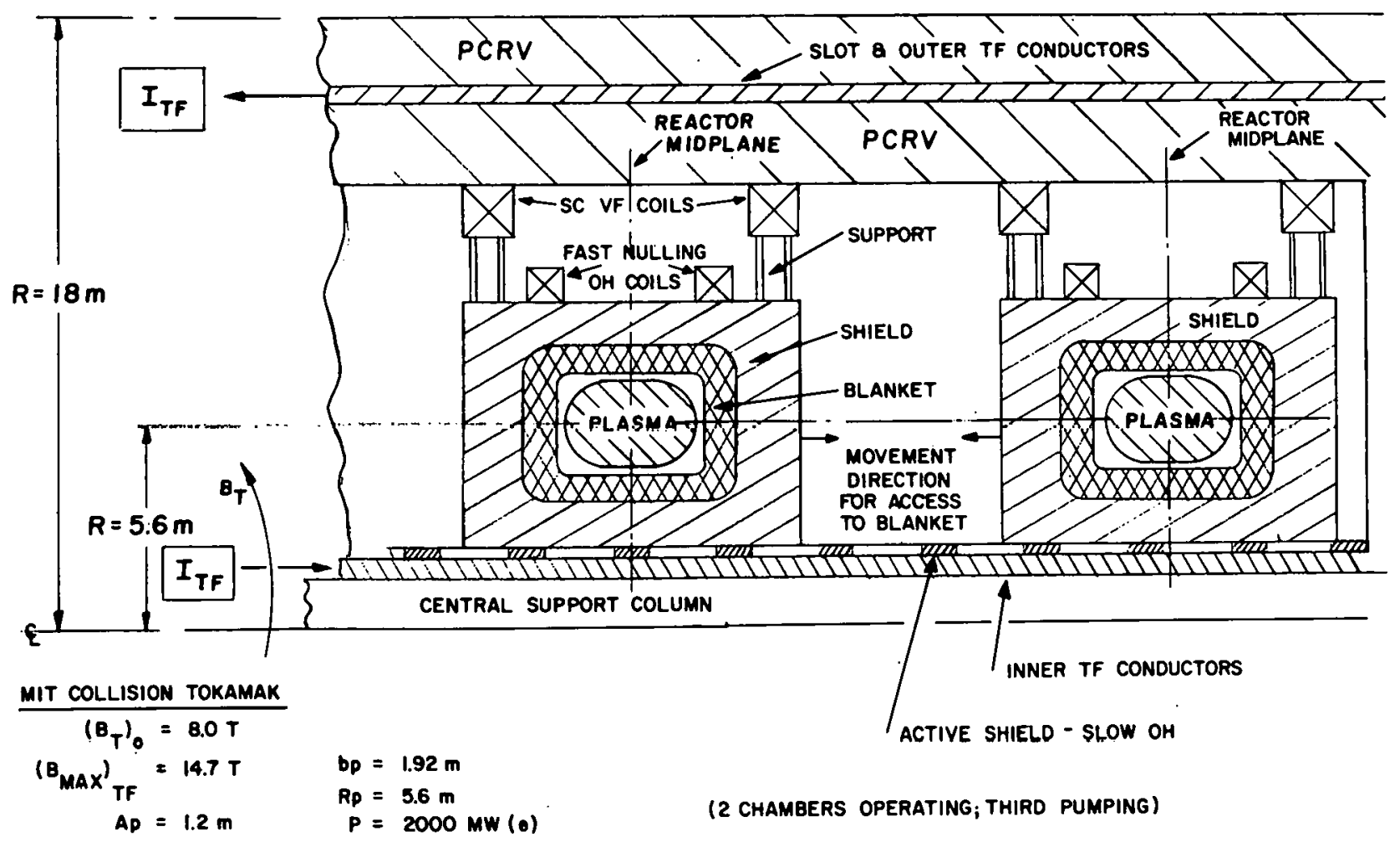

Figure 2.9. The multimak (multiple plasma chamber tokamak). 


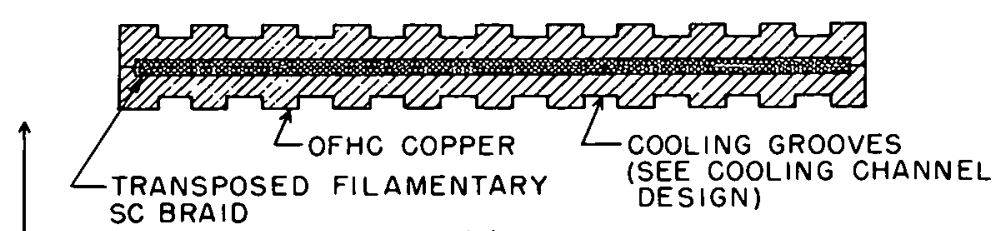

(a)

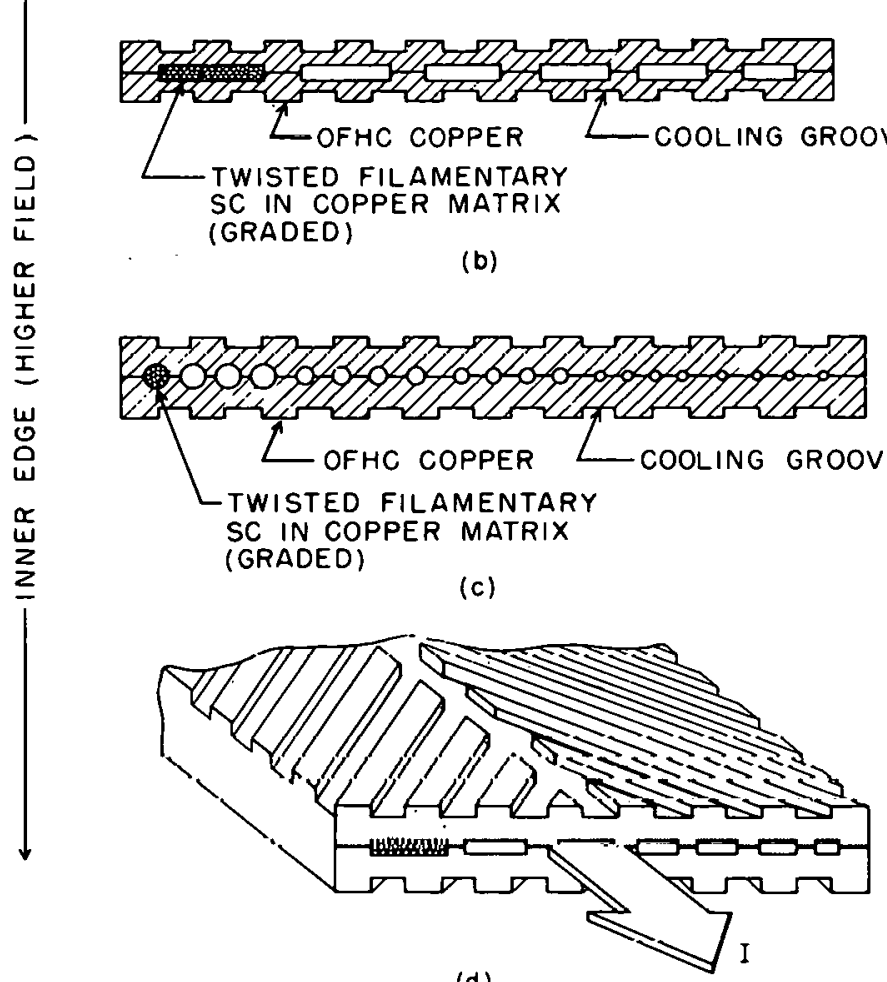

(d)

NOT TO SCALE

Figure 3.1. Conceptual conductor design. 


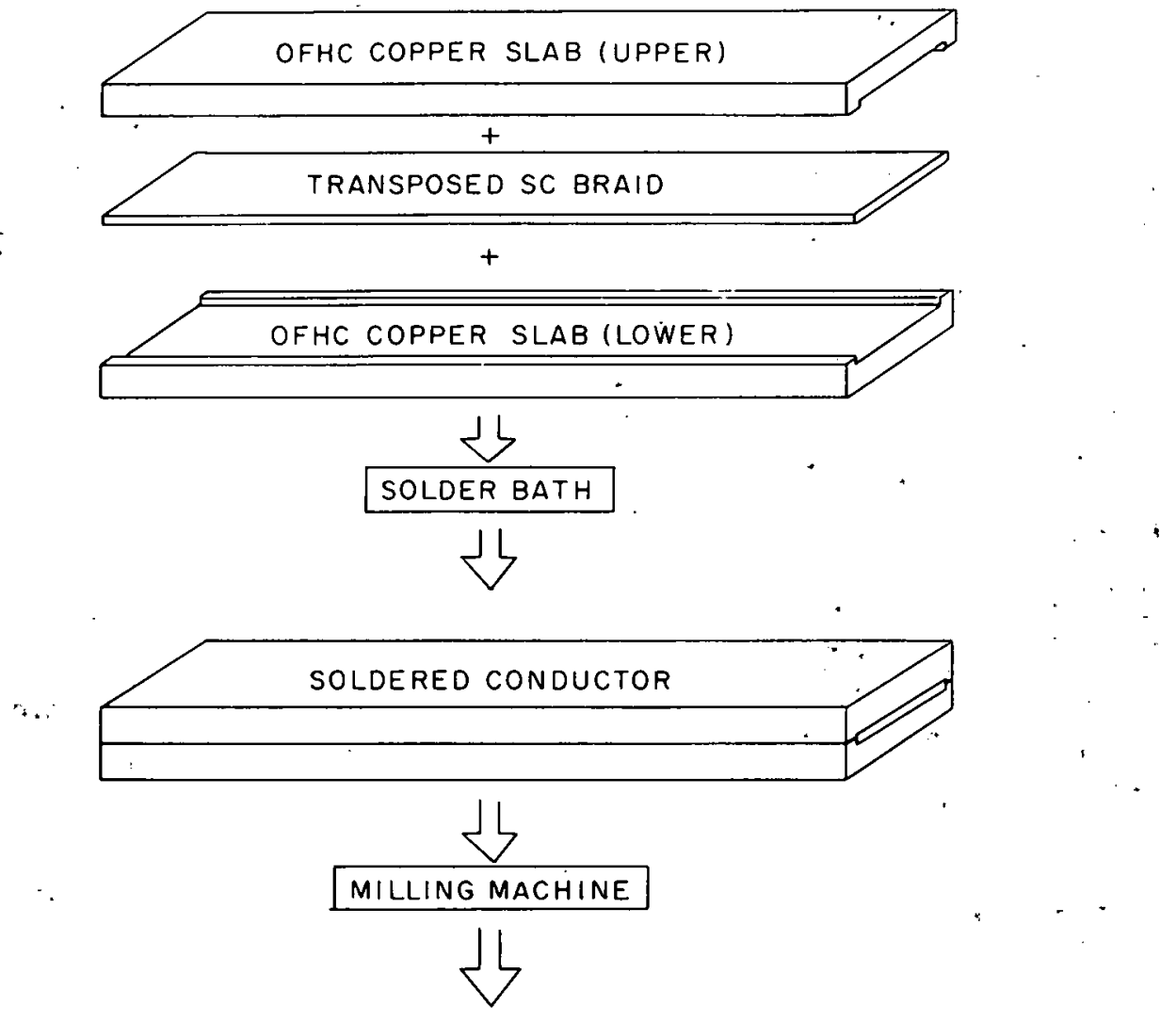

FABRICATED CONDUCTOR WITH COOLING GROOVES AND REQUIRED DIMENSIONS (SEE CONDUCTOR END DESIGN)

NOT TO SCALE

Figure 3.2. Schematic diagram of conductor fabrication process (1). 

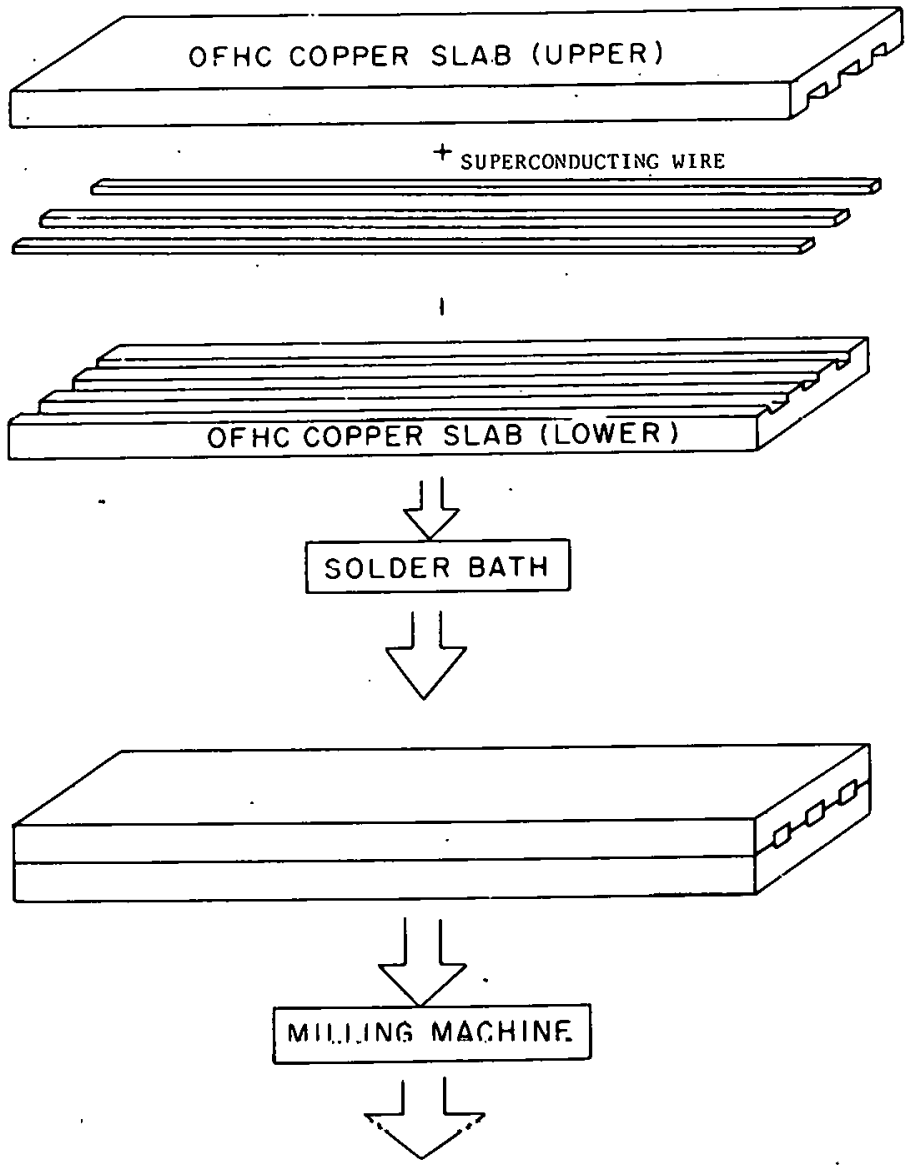

FABRICATED CONDUCTOR WITH COOLING GROOVES AND REQUIRED DIMENSIONS

(SEE CONDUCTOR END DESIGN)

NOT TO SCALE

Figure 3.3. Schematic diagram of conductor fabrication pronesss (2). 


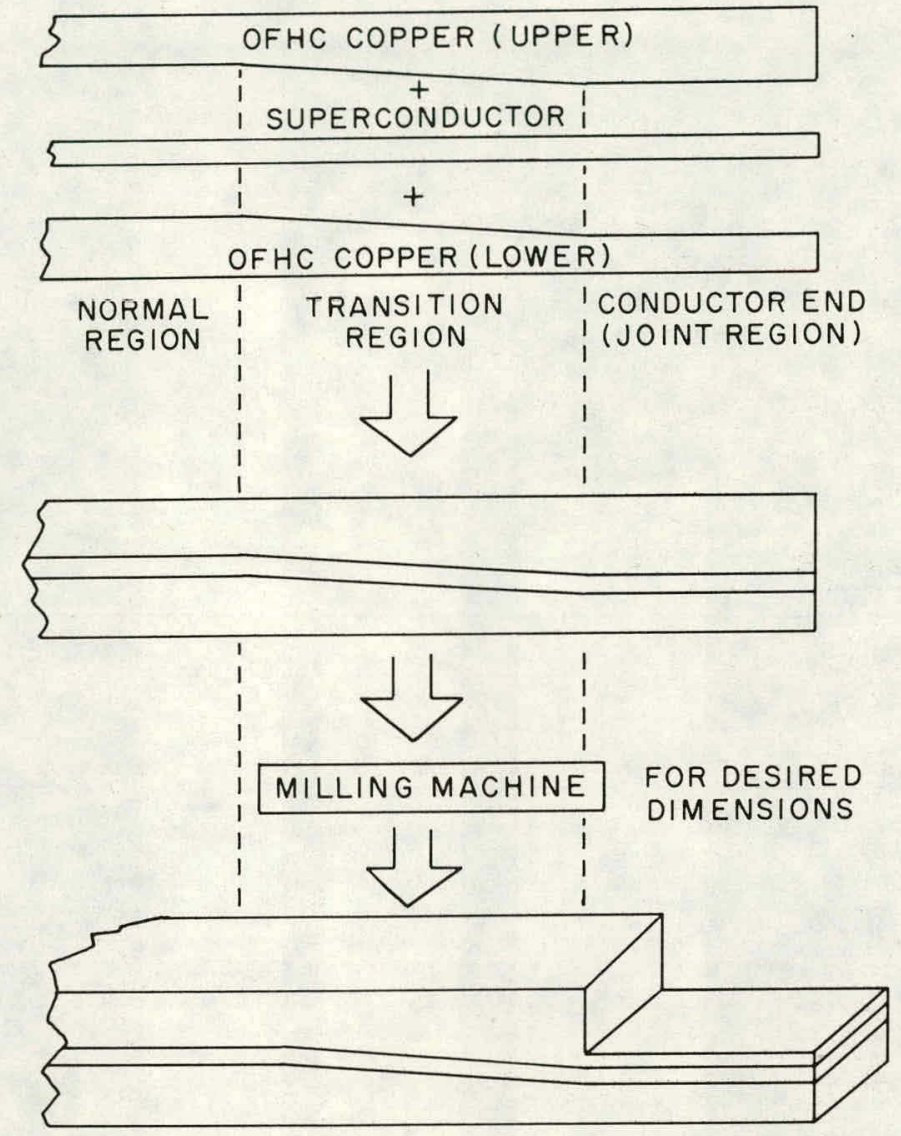

NOT TO SCALE

Figure 3.4. Schematic diagram of conductor fabrication process (3). 


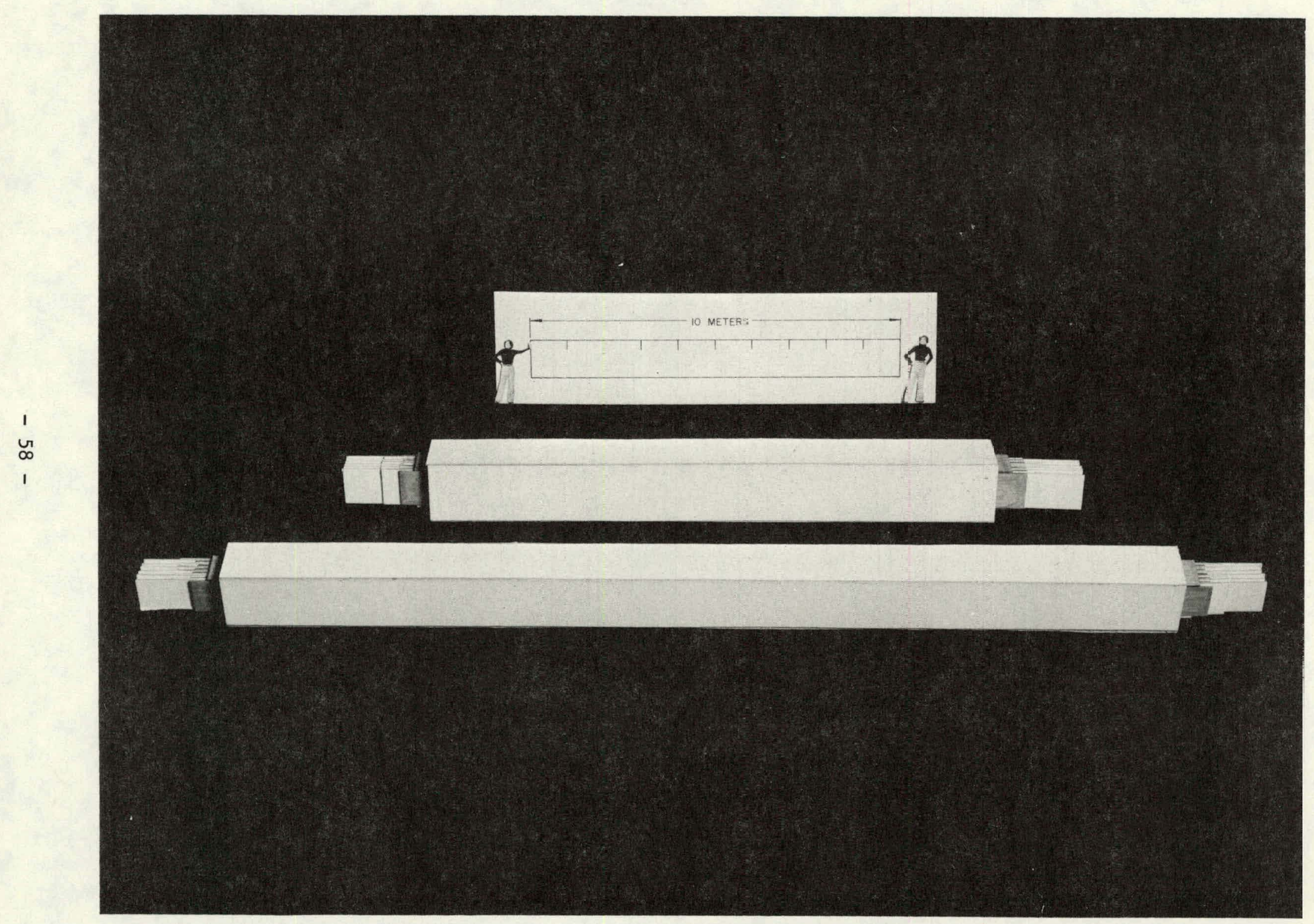

Figure 3.5. Model deals coil segments. 


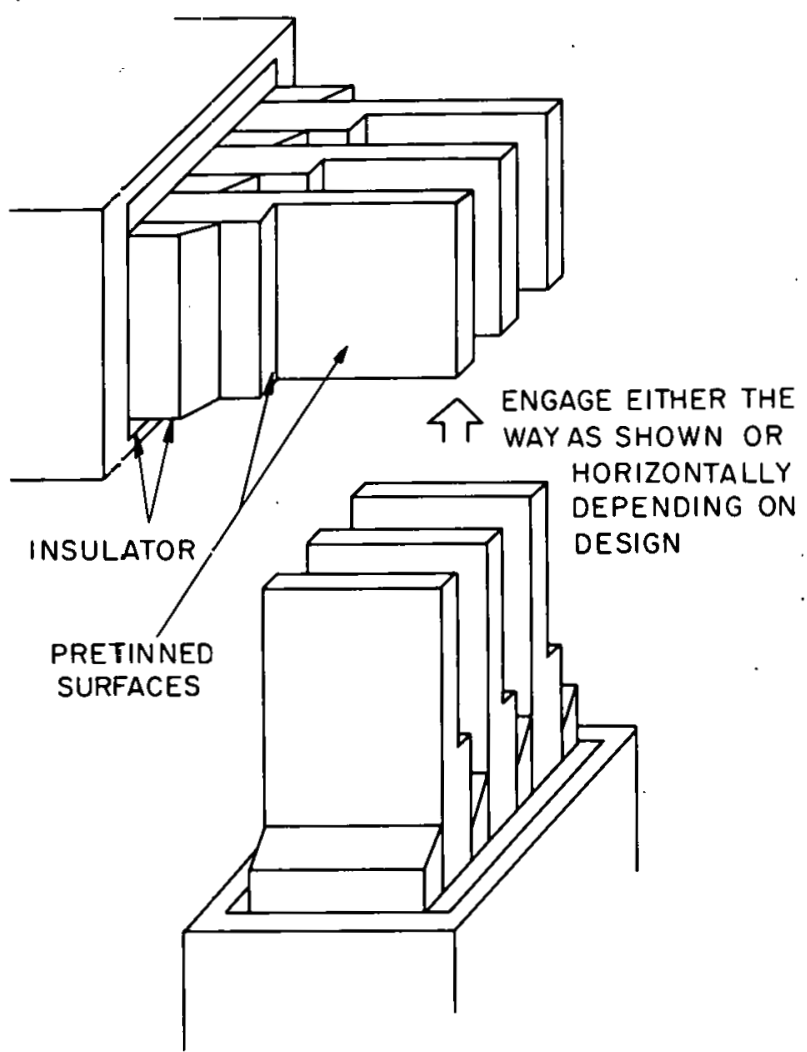

NOT TO SCALE

Figure 3.6. Schematic diagram of coil segment joining process (1).

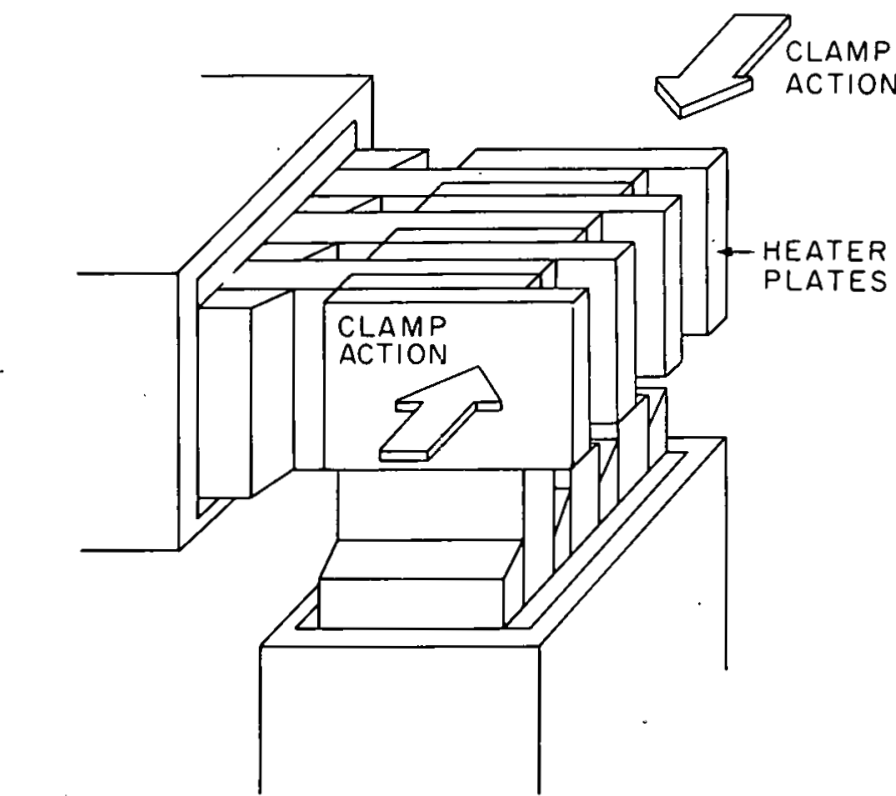

(1) INSULATED CLAMP APPLIED TO THE JOINT TO MAKE GOOD CONTACT BETWEEN CONDUCTOR TINNED SURFACES AND ALSO THE HEATER PLATES.

(2) WHEN PROPER SOLDERING ACTION IS FINISHED, HEATER IS TURNED OFF WITH CLAMP ON.

(3) CLAMP AND HEATEFS ARE REMOVED WHEN THE JOINT RETURNS TO ROOM TEMPERATURE.

NOT TO SCALE

Figure 3.7. Schematic diagram of coil segment joining process (2). 


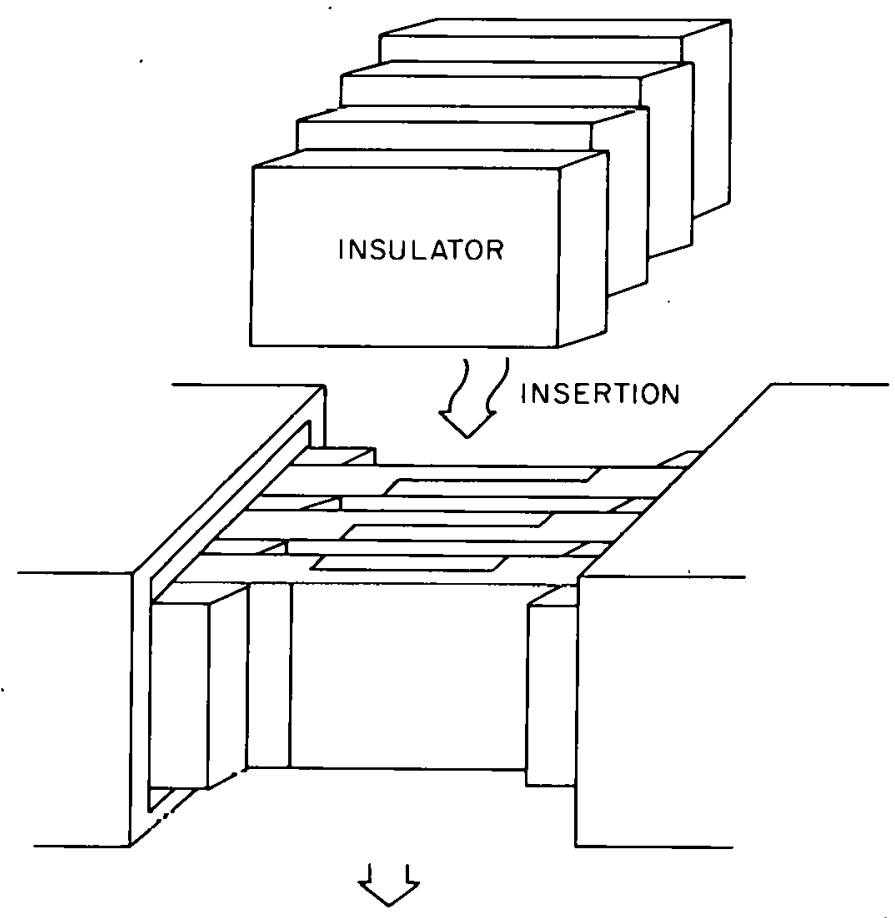

FOLLOWED BY SIDE INSULATION AND CASE WELDING AND REINFORCEMENT

NOT TU SCALE

Figure 3.8. Schematic diagram of coil segment joinling procusis (3). 


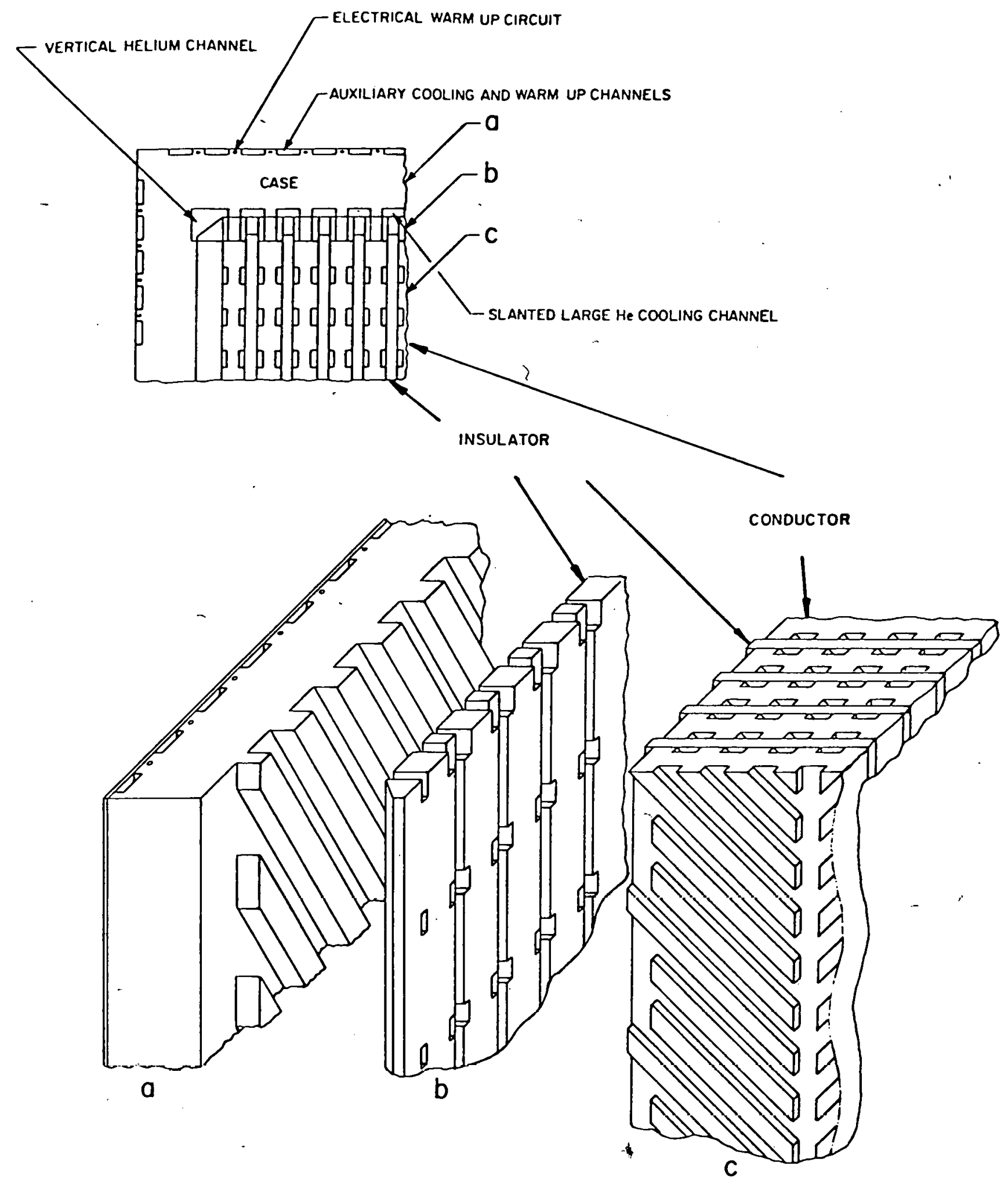

NOT TO SCALE

Figure 3.9. Conceptual pool cooling channel design. 


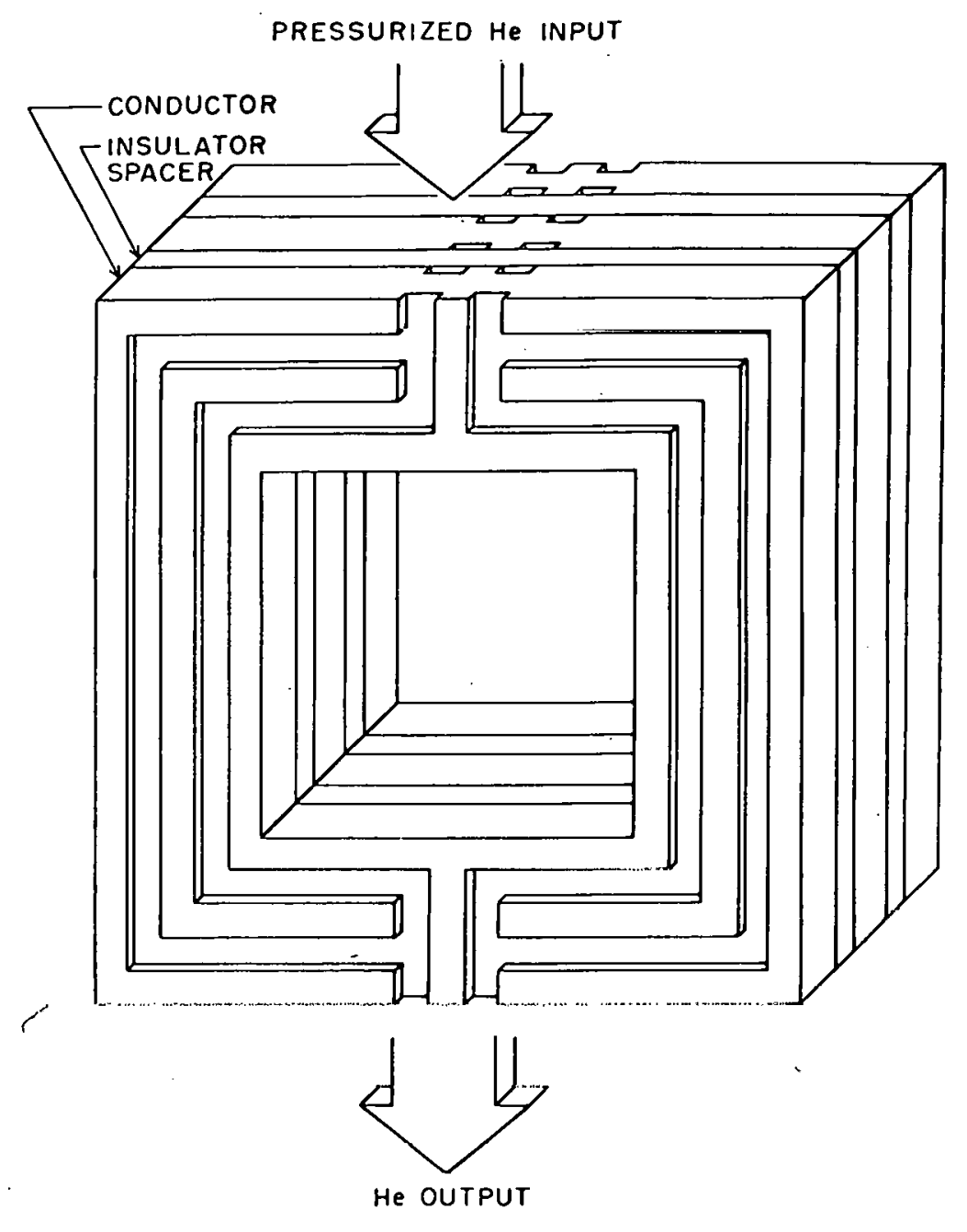

NOT TO SCALE

Figure 3.10. Conceptual force cooling channel design. 


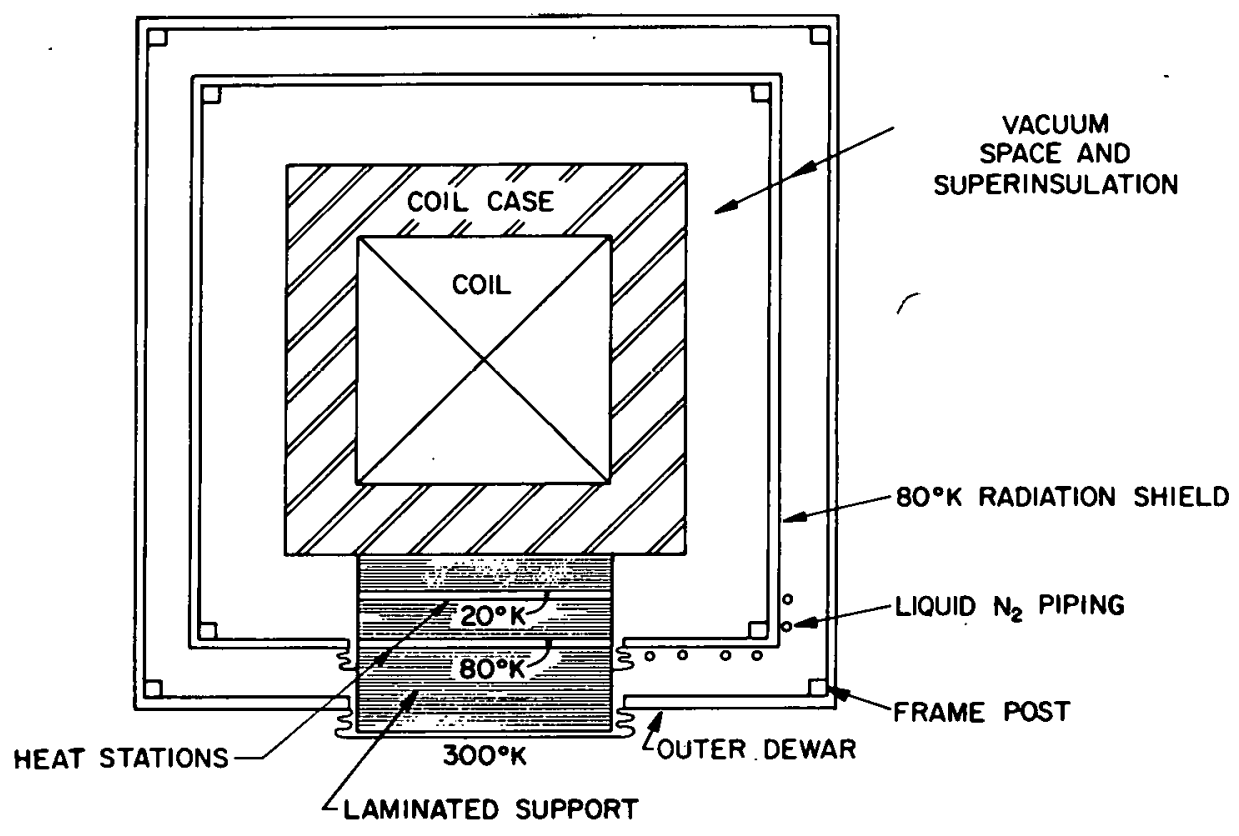

NOT TO SCALE

Figure 4.1. Cross-section of Dewar design. 


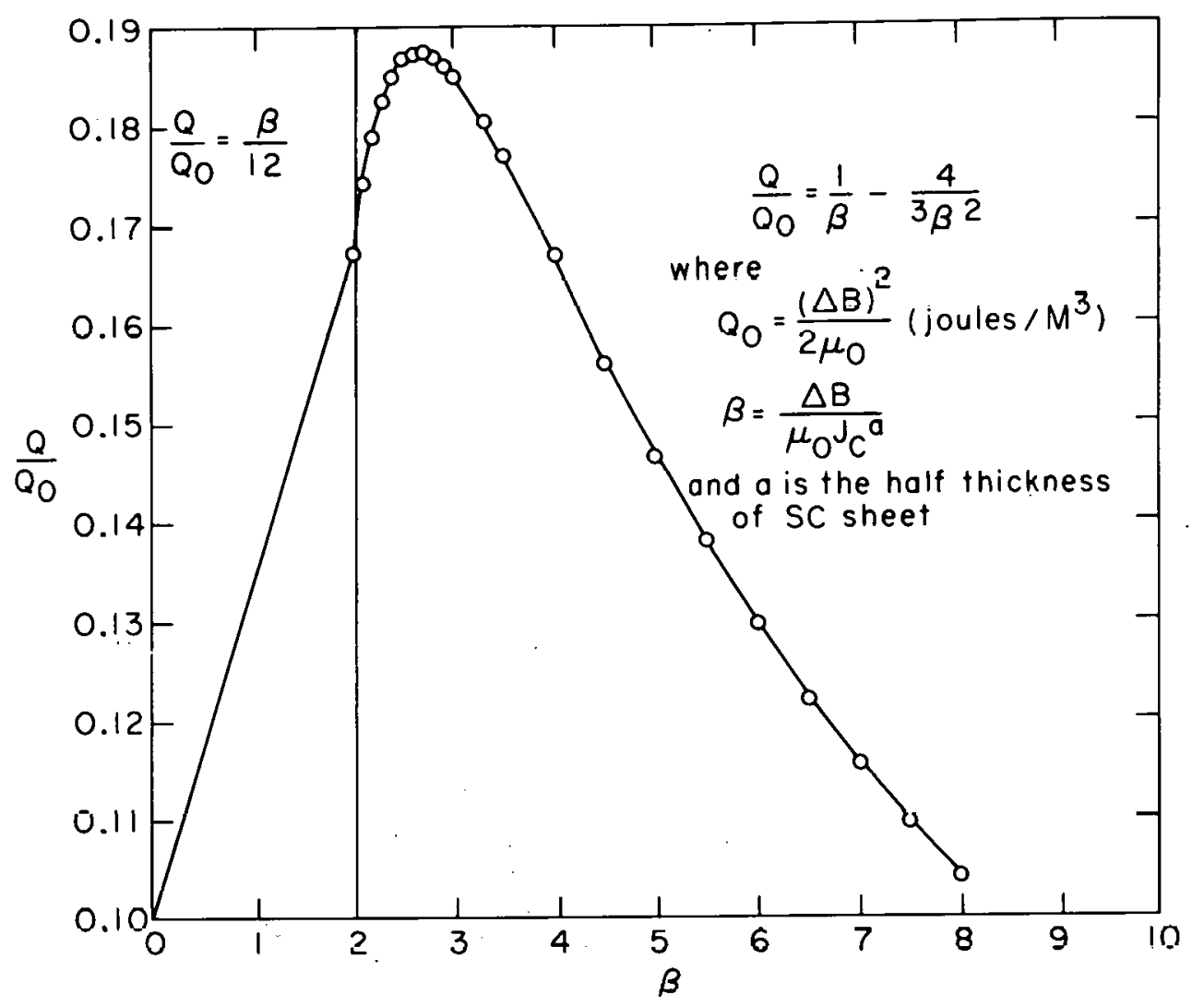

Figure 5.1. Hystcresis loss as a function of $B$. 


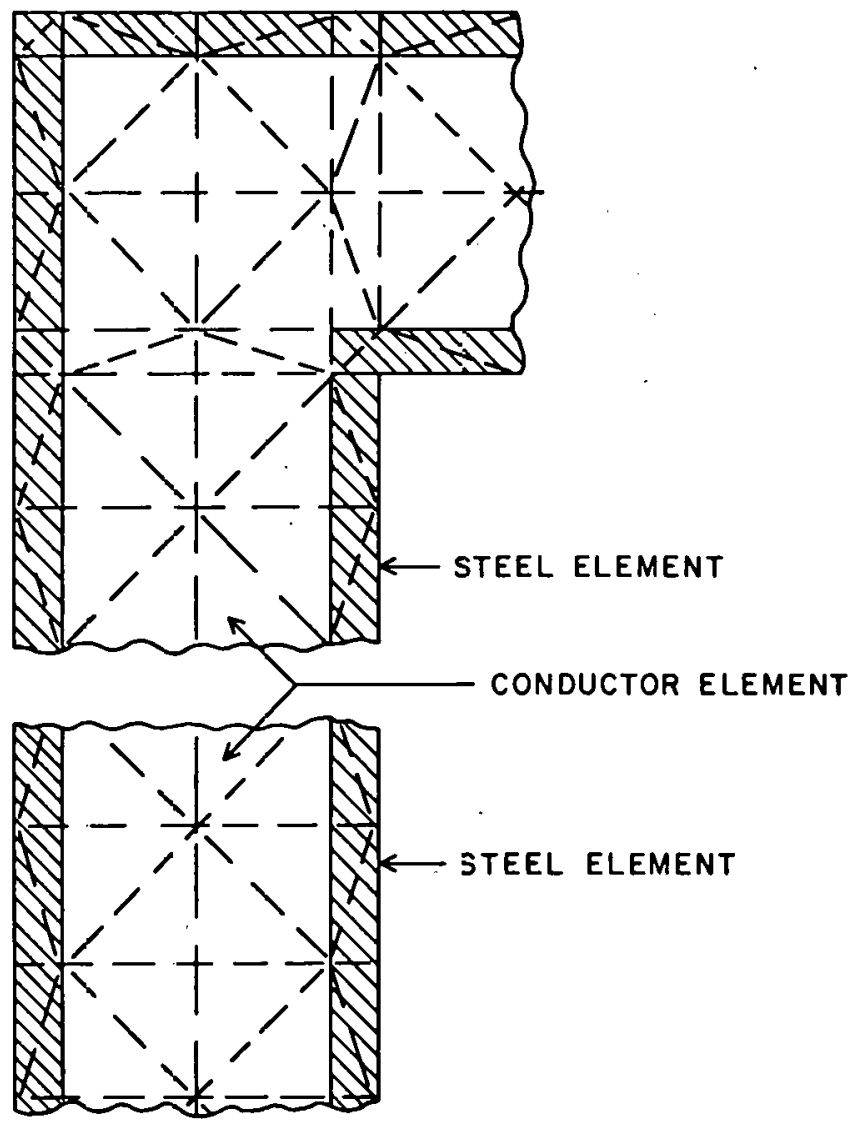

Figure 6.1. Finite elemert grid for whole coll stress anclysis.

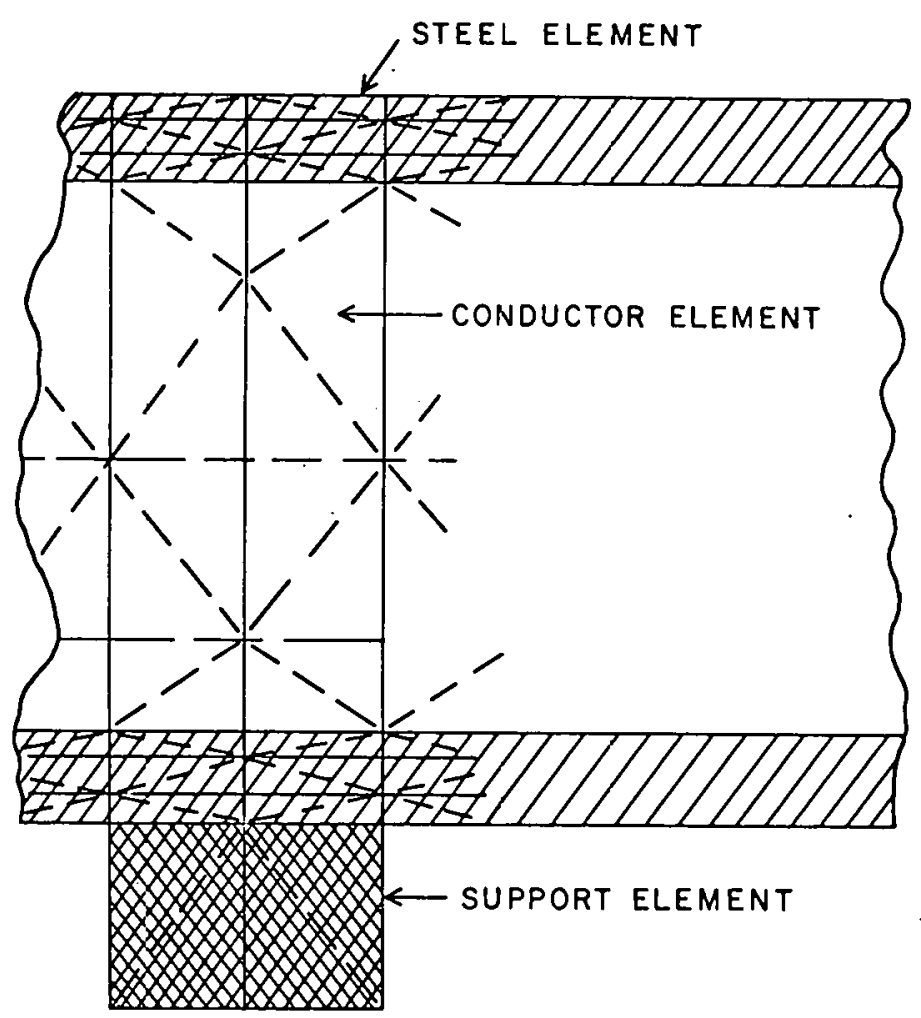

Figure 6.2. Finite element grid for individual coll leg stress analysis. 


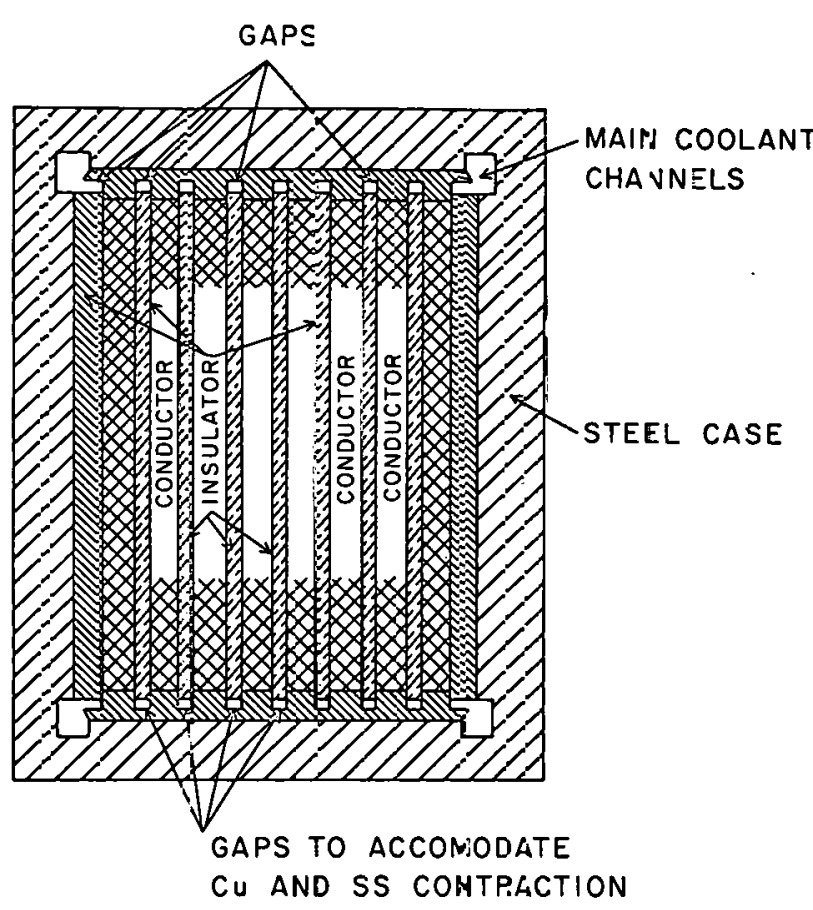

Figure 6.3. Coil cross-section with gaps for thermal contraction compensa:ion.

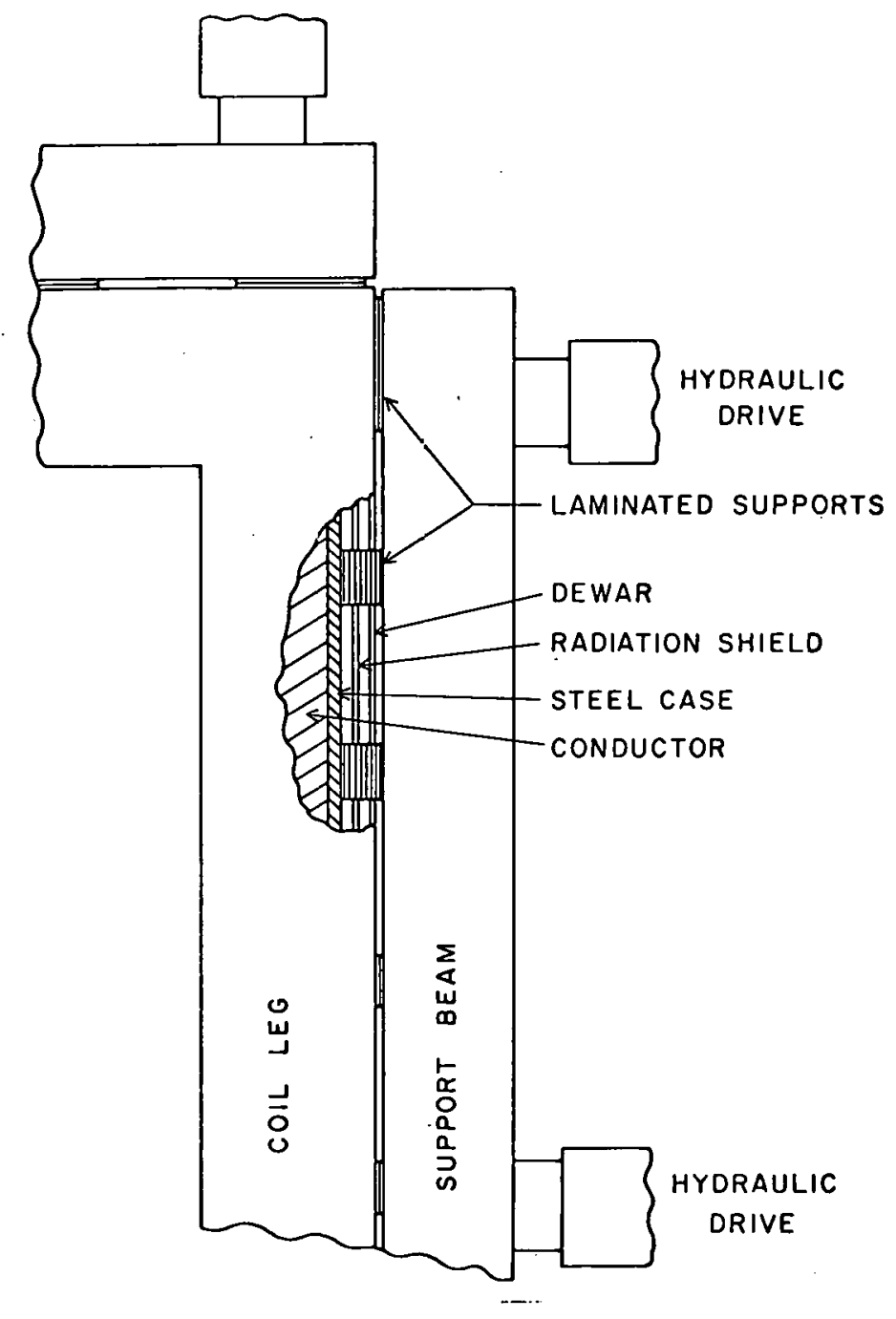

Figure 6.4. Co1l support system. 

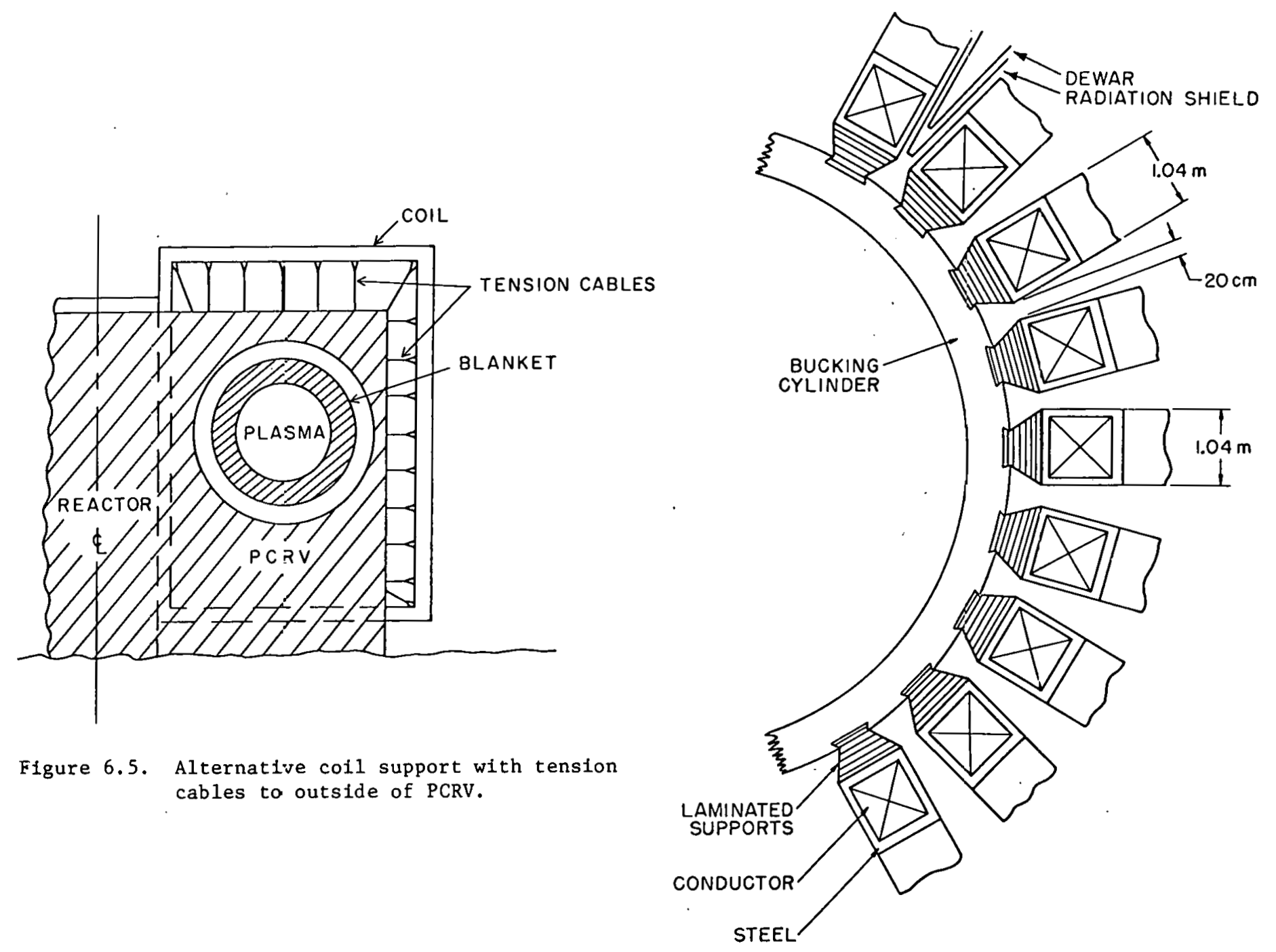

Figure 6.5. Alternative coil support with tension cables to outside of PCRV.

STEEL

Figure 6.6. Bucking column and coils Indicating spacing for Dewar and radiation shield. 

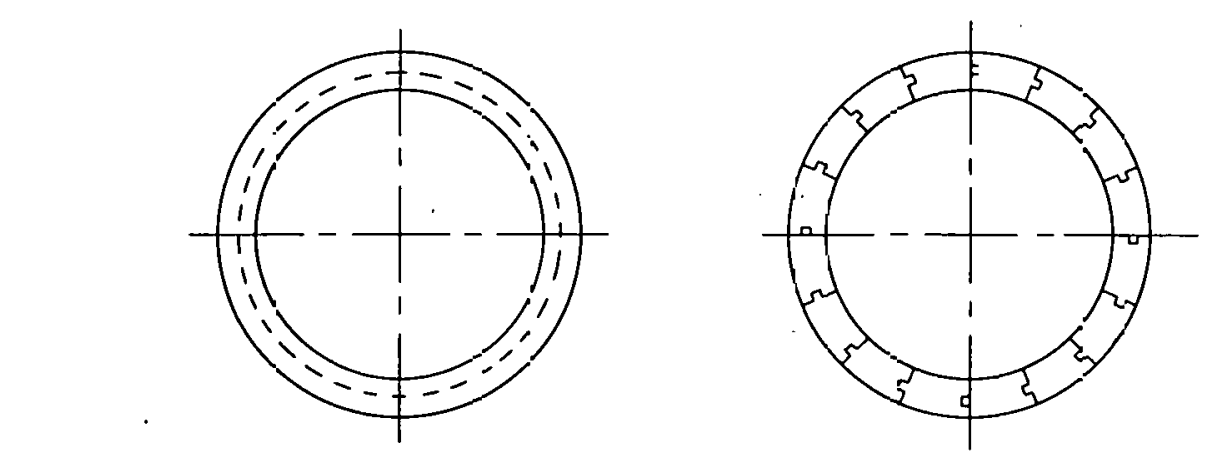

a

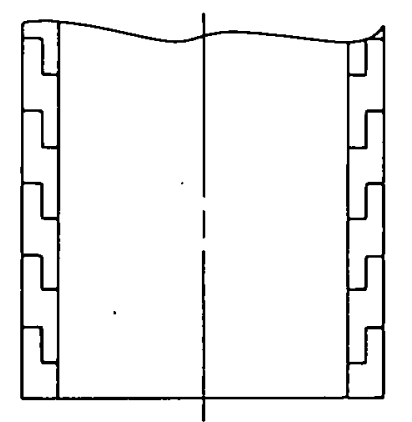

RING SEGMENTS

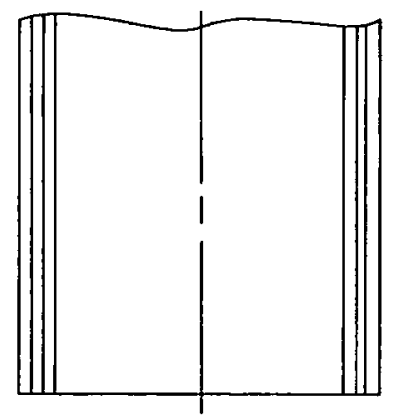

LONGITUDINA_ SEGNENTS

Figure 6.7. Central bucking column arrangements.

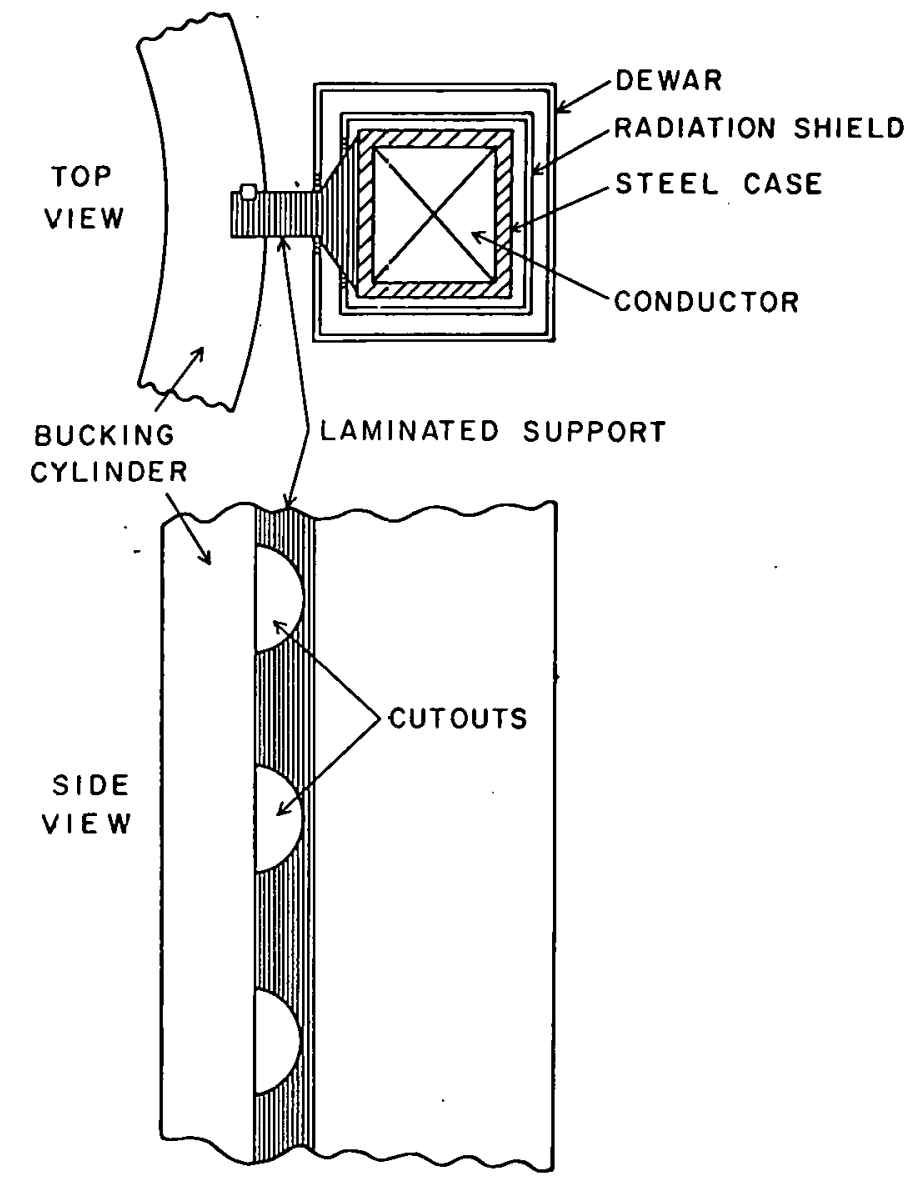

Figure 6.8. Coll supports for warm central column. 

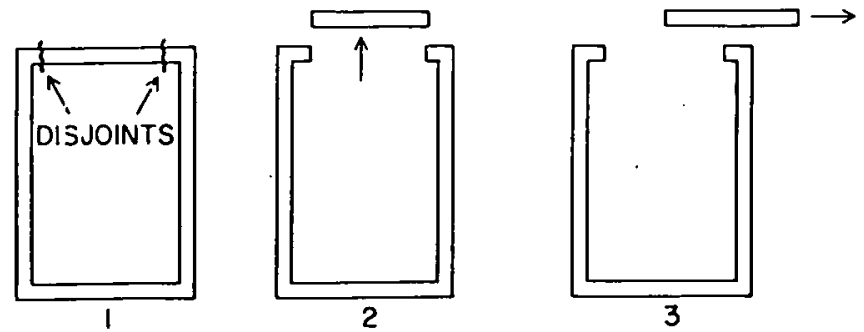

REMGIVL OF TOP (HORIZONTAL) SECTION

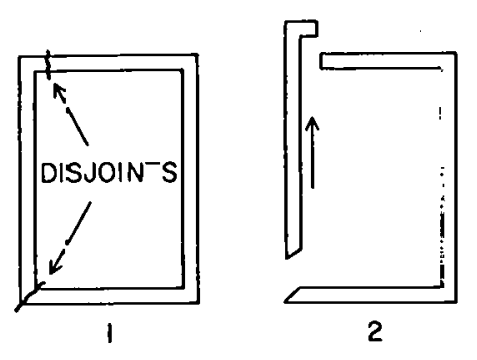

REMOVAL OF INSIDE VERTICAL LEG
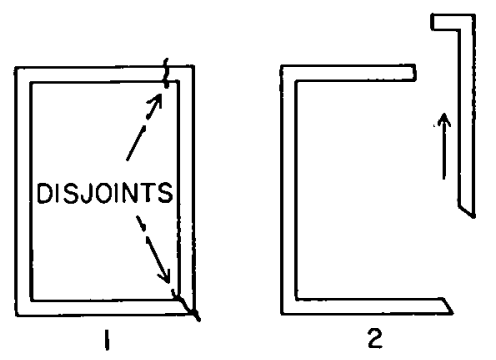

REMOVAL OF OUTSIDE VERTICAL LEG

Figure 6.9. Alternative four joint leg removal scheme.
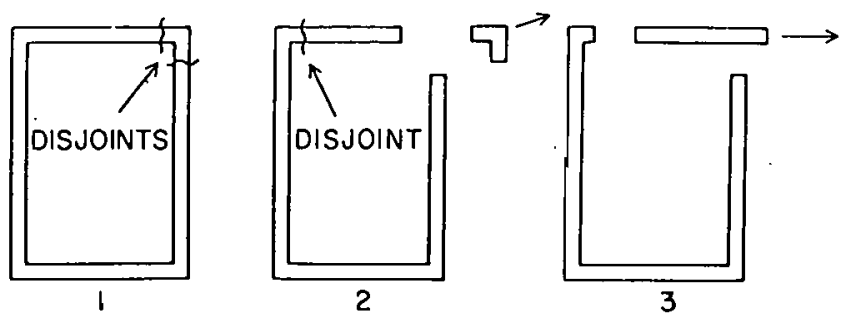

REMOVAL OF TOP (OR BOTTOM) SECTION

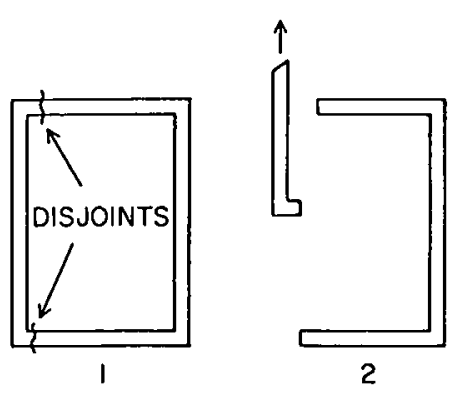

REMOVAL OF INSIDE VERTICAL LEG
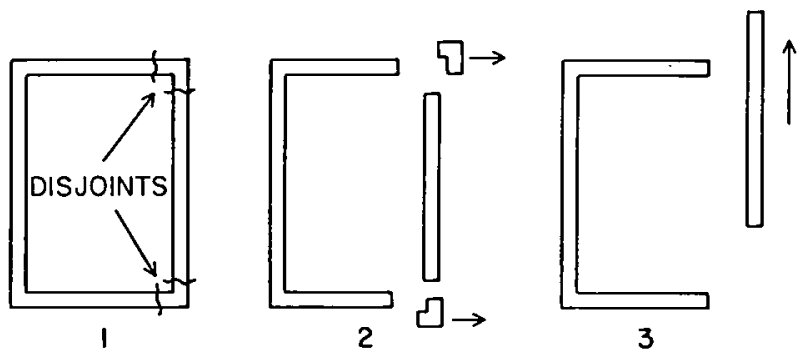

REMOVAL OF OUTSIDE VERTICAL LEG

Figure 6.10. Six joint leg removal scheme. 


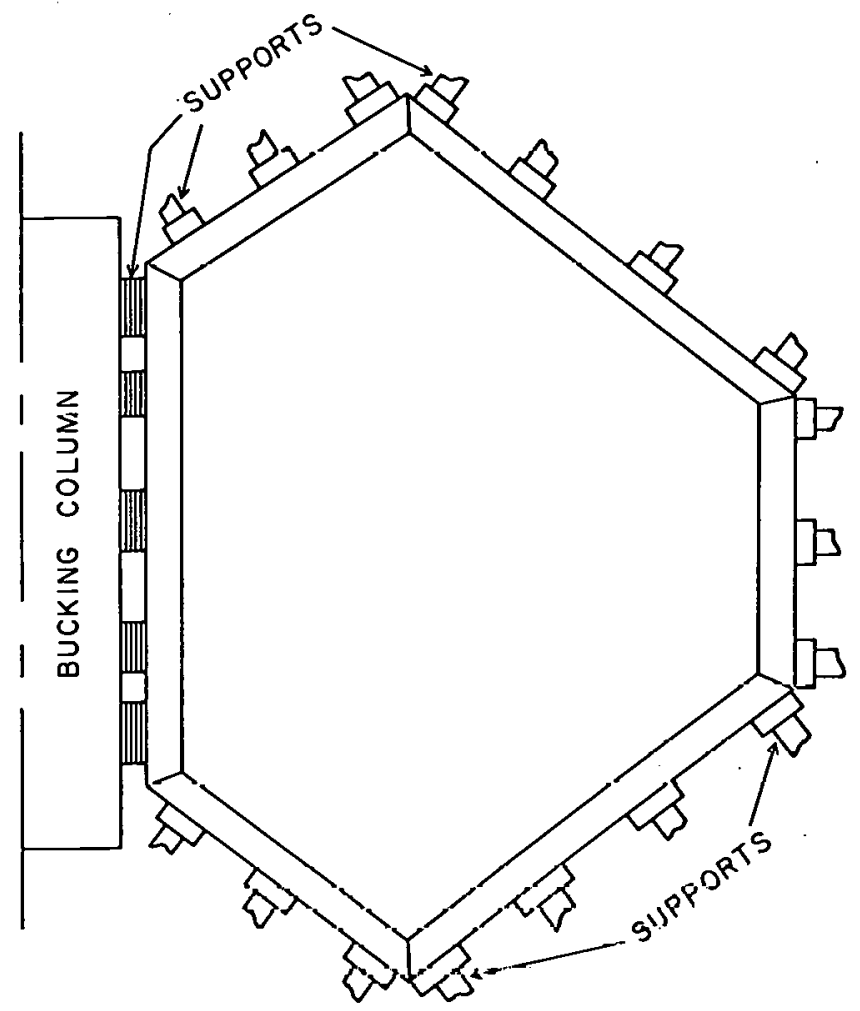

POLYGONAL SEGMENTED COIL

Figure 6.11. Polygonal coil made of six straight segments and externally supported. 




Figure 6,12. Vertical bucking column segments keyed to each coil. 


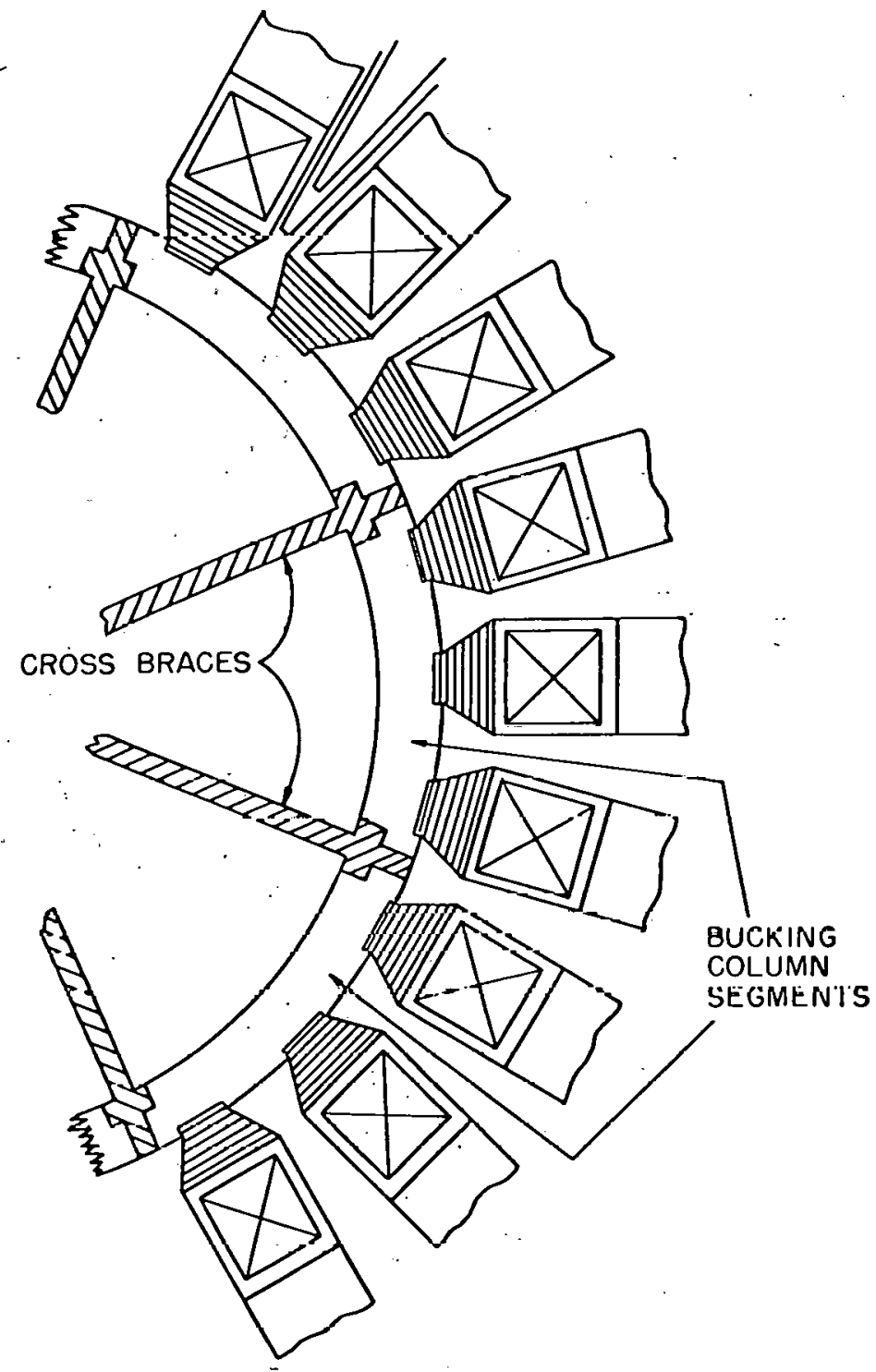

Figure 6.13. Segmented bucking column designed for pulling inside coil leg inward and up for removal. 